\title{
Results of the fourth Technology Centre Mongstad campaign: LVC testing
}

Loldrup Fosbøl, Philip; Neerup, Randi; Almeida, Susana; Rezazadeh, Amirali; Gaspar, Jozsef; Nesse Knarvik, Anette Beate; Enaasen Flø, Nina

Published in:

International Journal of Greenhouse Gas Control

Link to article, DOI:

10.1016/j.ijggc.2019.06.025

Publication date:

2019

Document Version

Peer reviewed version

Link back to DTU Orbit

Citation (APA):

Loldrup Fosbøl, P., Neerup, R., Almeida, S., Rezazadeh, A., Gaspar, J., Nesse Knarvik, A. B., \& Enaasen Flø, N. (2019). Results of the fourth Technology Centre Mongstad campaign: LVC testing. International Journal of Greenhouse Gas Control, 89, 52-64. https://doi.org/10.1016/j.ijggc.2019.06.025

\section{General rights}

Copyright and moral rights for the publications made accessible in the public portal are retained by the authors and/or other copyright owners and it is a condition of accessing publications that users recognise and abide by the legal requirements associated with these rights.

- Users may download and print one copy of any publication from the public portal for the purpose of private study or research.

- You may not further distribute the material or use it for any profit-making activity or commercial gain

- You may freely distribute the URL identifying the publication in the public portal 


\title{
Results of the fourth Technology Centre Mongstad campaign: LVC testing
}

\author{
Philip Loldrup Fosb $ø 1^{1 *}$, Randi Neerup ${ }^{1}$, Susana Almeida ${ }^{1}$, Amirali Rezazadeh ${ }^{1}$, Jozsef \\ Gaspar $^{1}$, Anette Beate Nesse Knarvik ${ }^{2}$, Nina Enaasen Flø ${ }^{2}$ \\ ${ }^{I}$ Center for Energy Resource Engineering (CERE), Department of Chemical Engineering, Technical University of Denmark (DTU), S $\phi l$ tofts \\ Plads, Building 229, DK-2800 Kongens Lyngby, Denmark \\ ${ }^{2}$ Technology Centre Mongstad (TCM DA), 5954 Mongstad, Norway
}

\begin{abstract}
The lean vapor compressor (LVC) unit at Technology Centre Mongstad (TCM), Norway has been tested using 30 wt\% monoethanol amine (MEA) and flue gas from the combined cycle gas turbine (CCGT) based combined heat and power (CHP) plant. The aim was to study the impact of $\mathrm{LVC}$ on the $\mathrm{CO}_{2}$ capture efficiency and energy profile of the TCM plant. 16 cases have been tested with and without LVC, and with various process parameters such as LVC pressure, solvent flow, inlet flue gas $\mathrm{CO}_{2}$ concentration, and stripper pressure. Absorber and stripper process conditions were recorded during these tests.
\end{abstract}

The operation of the TCM amine plant was very steady. Standard deviation and reproducibility of the various process parameters were satisfactory.

Overall, the LVC results are as expected. A clear trend shows lower operating LVC pressure gives less specific reboiler energy consumption. A maximum thermal energy reduction of $25 \%$ was obtained when applying LVC at the expense of a typical LVC electrical energy consumption of 0.1 to $0.2 \mathrm{GJ}$ electric/ton $\mathrm{CO}_{2}$.

Additional results show that the specific reboiler duty (SRD) may have a characteristic non-linear dependence on solvent flow rate. Higher stripper pressure may decrease the specific reboiler duty and be beneficial to the thermal power used in the plant at the expense of increased LVC electrical power consumption.

Lower SRD was obtained when increasing the inlet flue gas $\mathrm{CO}_{2}$ concentrations both with and without LVC. For the LVC cases, no significant indication of additional energy requirement was observed when increasing the $\mathrm{CO}_{2}$ capture rate.

The LVC power consumption in this study was to a large extend conservative due to a specific LVC design chosen.

The presented results will help to enhance the accuracy of future $\mathrm{CO}_{2}$ capture engineering designs.

Keywords: Lean Vapor Compression (LVC); Specific Reboiler Duty (SRD); Monoethanolamine (MEA); $\mathrm{CO}_{2} \mathrm{Capture}$ and Storage (CCS); Technology Centre Mongstad (TCM); Process Optimization

${ }^{*}$ Corresponding author. Tel.: +45 45252868; fax: +45 45882258.

E-mail address: plf@kt.dtu.dk 


\section{Introduction}

Amine absorption is considered a suitable and proven technology for $\mathrm{CO}_{2}$ capture. The major drawback of the technology is the high energy demand for regeneration of the solvent. There are two ways of improving the energy performance. First by solvent development and secondly by process optimization such as intermediate stripper heating, improved heat integration, absorber intercooling, and lean vapor compression [1]-[3].

Lean vapor compression (LVC) is an interesting option for process optimization in $\mathrm{CO}_{2}$ capture. In this configuration, the lean solvent stream from the stripper is flashed and the formed vapor is compressed and re-injected in the bottom of the stripper while the lean amine is circulated back to the lean amine solvent loop. LVC has already been proven to be technically feasible and able to reduce the thermal energy consumption, as demonstrated in the CESAR project [4]. One of the CESAR aims was to show the effect of implementing LVC and/or inter-cooling to the Esbjerg pilot plant. By experiments and simulation, it was shown that the LVC had better effect than inter-cooling. Taking into account the extra compression work the net decrease in reboiler duty was $6 \%$ at atmospheric pressure. LVC was also investigated by Le Moullec and Kanniche [5], [6]. They presented a reduction in plant energy penalty of approximately $11 \%$. Dubois and Thomas [3] concluded that LVC configuration leads to higher energy savings compared to conventional configurations with a specific regeneration energy lower than $3 \mathrm{GJ} / \mathrm{t} \mathrm{CO}_{2}$. In the work by Sanchez Fernandez et al.[1] two scenarios were evaluated based on maximizing the net present value (NPV) of the process savings: 1) a capture plant fully adapted to the effect of LVC and 2) LVC retrofitted to a basic capture plant design. They found that the NPV of the two LVC scenarios was positive and attractive from a financial point of view. There are new unconventional high temperature stripper configurations which may lead to a performance similar or better than LVC, [7], [8]. A sub-conclusion of these configurations shows that the LVC power consumption will increase with stripper pressure.

Technology Centre Mongstad (TCM) in Norway is the world's largest facility for testing $\mathrm{CO}_{2}$ capture. TCM collaborates with academia and industry by offering operational test hours from the MEA campaigns to researchers. In June 2017, TCM started a series of test campaigns (MEA-3, MEA-4 and MEA-5) to investigate the underlying process optimization and cost reduction possibilities for a system using monoethanolamine (MEA) as solvent for $\mathrm{CO}_{2}$ capture [7]. The LVC campaign described in the present work was running for two weeks in June 2018 as part of the MEA-4 campaign.

The main objective of the MEA-4 campaign was to produce knowledge and information that can be used to reduce the cost as well as technical, environmental and financial risks of commercial scale $\mathrm{CO}_{2}$ capture deployment. The aim of the present work is to study the impact of the LVC performance of the TCM plant by varying the following process conditions:

1. LVC pressure

2. Solvent flow rate

3. Stripper pressure

4. $\mathrm{CO}_{2}$ content in feed gas

5. $\mathrm{CO}_{2}$ capture rate

There are several stakeholders focused on full-scale carbon capture and storage (CCS) demonstration. Many industries around the world could significantly benefit from full-scale implementations of CCS, like the cement industry, ammonia production and waste incineration. There will be many future CCS sites which will rely on reducing the energy consumption on the entire process, which in the end will reduce the cost.

The objective of this study is to investigate the operation of the $\mathrm{LVC}$ unit and the impact on the $\mathrm{CO}_{2}$ capture process and energy consumption. It is the first time that results are presented from testing LVC at the world's largest test facility for $\mathrm{CO}_{2}$ capture. The results may lead to better Front End Engineering Design (FEED) studies in the future. 


\begin{tabular}{|ll}
\hline Nomenclature \\
CCGT & Combined Cycle Gas Turbine \\
CCS & Carbon Capture and Storage \\
CESAR & CO $_{2}$ Enhanced Separation and Recovery \\
CHP & Combined Heat \& Power \\
DCC & Direct Contact Cooler \\
FEED & Front End Engineering Design \\
FTIR & Fourier-Transform Infrared Spectroscopy \\
GC & Gas Chromatography \\
LVC & Lean Vapour Compression \\
MEA & Monoethanolamine \\
NDIR & Non-Dispersive Infrared \\
NPV & Net Present Value \\
PCC & Post-Combustion Capture \\
SRD & Specific Reboiler Duty \\
SS & Steady State \\
TCM & Technology Centre Mongstad \\
TIC & Total Inorganic Carbon
\end{tabular}




\section{Description of test facility and campaign outline}

In June 2018 a LVC test campaign was performed at Technology Centre Mongstad using aqueous 30 wt\% MEA and flue gas supplied by the combined cycle gas turbine (CCGT) based combined heat and power (CHP) plant at the nearby Equinor refinery. The testing was conducted in the amine plant designed and constructed by Aker Solutions and Kværner. The LVC compressor (Pinnacle LF2140 single stage) was manufactured by Sundyne Compressors. The vendor design specification gives a compressor efficiency of approximately $80 \%$.

A simplified process flow diagram showing the TCM amine plant configuration with CCGT based CHP flue gas feed, $\mathrm{CO}_{2}$ recycle, and the large stripper designed for high $\mathrm{CO}_{2}$ content flue gas is illustrated in Figure 1. This set-up was utilized in the LVC test campaign.

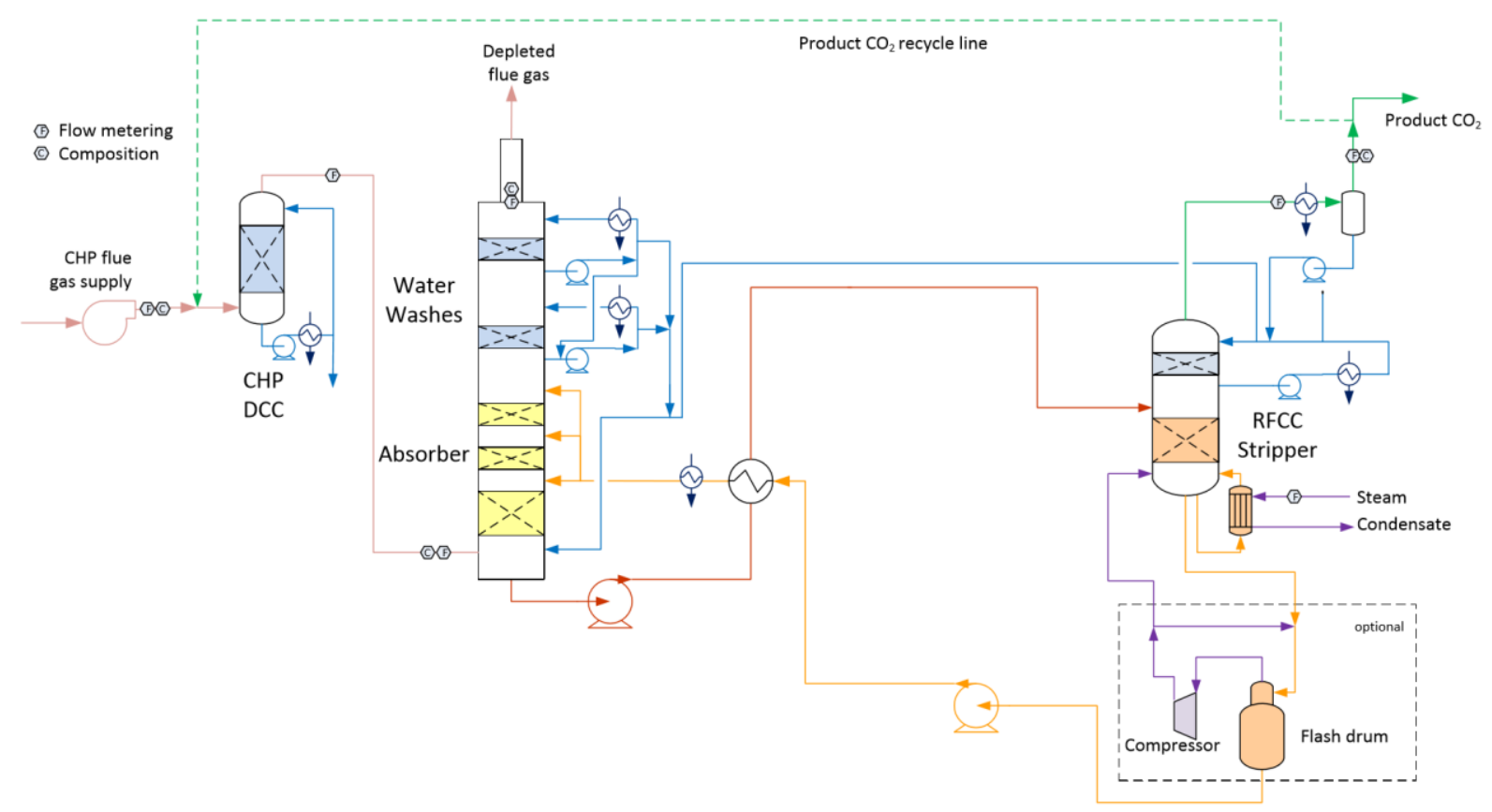

Figure 1. Simplified process flow diagram of the TCM amine plant configured with CCGT based CHP gas and $\mathrm{CO}_{2}$ recycle.

The CHP flue gas is conditioned in a direct contact cooler (DCC) after being enriched with $\mathrm{CO}_{2}$ from the $\mathrm{CO}_{2}$ product recycle stream. The conditioned flue gas is contacted counter-currently with amine solvent in the absorber. $\mathrm{CO}_{2}$ is absorbed, yielding a solvent rich in $\mathrm{CO}_{2}$ and a depleted flue gas with low $\mathrm{CO}_{2}$ content. The depleted flue gas is released to the atmosphere after being conditioned in the water wash sections. The rich solvent loaded with $\mathrm{CO}_{2}$ is pre-heated in the lean/rich cross heat exchanger before entering the stripper column. Additional heat is supplied by steam to the stripper reboiler in order to desorb $\mathrm{CO}_{2}$ and regenerate the solvent. The product $\mathrm{CO}_{2}$ gas is released to the atmosphere, while the regenerated lean solvent is pumped back to the absorber via the lean/rich cross heat exchanger and the lean cooler. The amine plant is described more in detail elsewhere [8]-[10].

The large stripper section designed for high $\mathrm{CO}_{2}$ content flue gas is also equipped with an optional lean vapour compressor system, as illustrated in Figure 1. In the LVC system (see Figure 2), hot lean amine exiting the stripper bottom is throttled to a lower pressure and fed to a flash drum generating vapour. The vapour is compressed and returned to the stripper bottom, while the lean amine is circulated back to the lean amine solvent loop. The superheated steam provides additional energy for regeneration of solvent in the stripper, which has the potential of reducing consumption of low pressure steam in the stripper reboiler. 


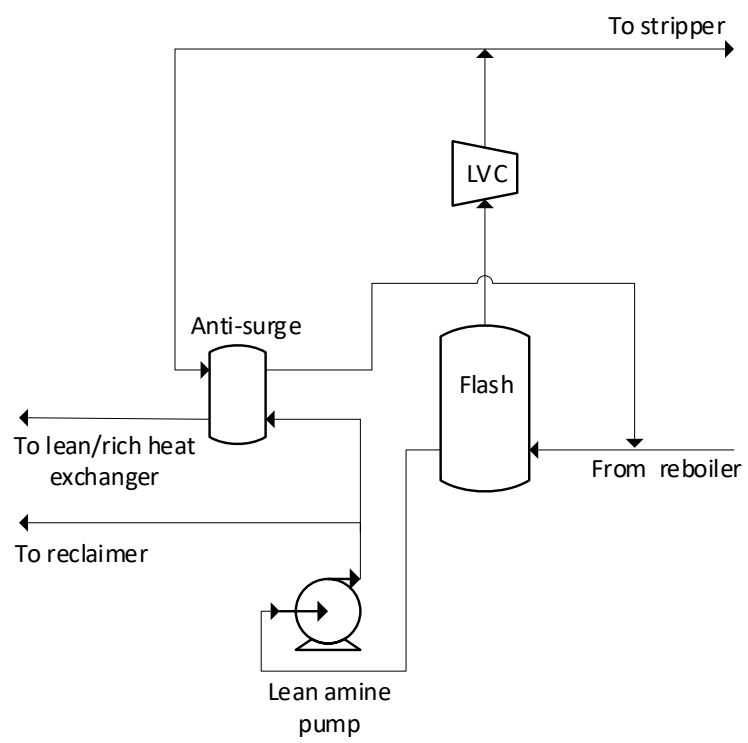

Figure 2. Simplified process flow diagram of the LVC.

The LVC campaign was a joint project between the Department of Chemical Engineering at the Technical University of Denmark (DTU) and TCM. The campaign was divided into two main categories: Base case without LVC (case 1, BASE), and an LVC test phase (case 2, LVC). Overall, 16 cases were performed with and without LVC. The flow rate of the flue gas was $35000 \mathrm{Sm}^{3} / \mathrm{h}$. The absorber and the stripper packing height were $18 \mathrm{~m}$ and $8 \mathrm{~m}$ respectively. Absorber and stripper were packed with structured Flexipac 2X.

Table 1 gives a general overview of the adjustable process parameters applied in the various cases during the LVC campaign at TCM.

Table 1. Overview of the 16 cases with respect to basic process parameters used.

\begin{tabular}{l|l}
\hline Case & Focus \\
\hline $1 \mathrm{~A}$ to $1 \mathrm{C}$ & Solvent flow rate \\
$1 \mathrm{D}$ & $\mathrm{CO}_{2}$ capture rate \\
$1 \mathrm{E}$ & Stripper pressure \\
$1 \mathrm{~F}$ & Inlet flue gas $\mathrm{CO}_{2}$ concentration \\
\hline $2 \mathrm{~A}$ to $2 \mathrm{C}-1$ & Solvent flow rate with $\mathrm{LVC}$ \\
$2 \mathrm{C}-1$ to $2 \mathrm{D}-2$ & $\mathrm{CO}_{2}$ capture rate and LVC pressure \\
$2 \mathrm{E}$ & Stripper pressure with $\mathrm{LVC}$ \\
$2 \mathrm{~F}$ & Inlet flue gas $\mathrm{CO}_{2}$ concentration with $\mathrm{LVC}$ \\
\hline
\end{tabular}

The campaign was operated in such a way that only one parameter was adjusted at a time allowing the plant to reach steady state much faster. The campaign was performed with case durations between 3 to 24 hours out of which 1 to 8 hours were used for calculation of average steady state conditions. Lean and rich solvent sampling was performed in the end of each case. The solvent samples were analysed in the TCM laboratory for total inorganic carbon (TIC) and total alkalinity giving the solvent $\mathrm{CO}_{2}$ and MEA concentrations, respectively.

The $\mathrm{CO}_{2}$ content in the gas at the absorber inlet, absorber outlet and $\mathrm{CO}_{2}$ product stream were continuously monitored during the campaign by online GC, FTIR, and NDIR analysers. The gas moisture content was also determined by GC, however in the present results it is estimated assuming the gas to be in equilibrium with pure water at the given conditions in the inlet flue gas, at the top of the absorber and in the $\mathrm{CO}_{2}$ product line. 


\section{Chemicals}

MEA (>97\%) was diluted with demineralized water to obtain a solvent concentration of $30 \mathrm{wt} \%$. Flue gas from the CCGT based CHP plant at Mongstad was utilized. The flue gas typically contained $3.6-4 \mathrm{vol} \% \mathrm{CO}_{2} . \mathrm{CO}_{2}$ product gas was recycled to increase the inlet flue gas $\mathrm{CO}_{2}$ concentration up to $11-14 \%$ for test purposes.

\section{Results and discussion}

\subsection{Campaign profiles}

A case overview of the LVC campaign is given in Figure 3. It shows the 16 cases which were performed. Each case starts with a grey dotted line, the following green and red dotted lines indicate the boundaries used for the steady state (SS) data. Note that in the time-intervals 11/6 13:00 to 12/6 14:30 and 15/6 7:00 to 15/6 12:00 data are not given, since the plant was not operated for the purpose of the LVC campaign. The various time intervals are given in Table 2. In addition to campaign timing, Table 2 gives basic process parameters such as solvent flow, stripper pressure, LVC pressure, inlet flue gas $\mathrm{CO}_{2}$ concentration and $\mathrm{CO}_{2}$ capture rate.

Table 2. Overview of the 16 cases with respect to basic process parameters used.

\begin{tabular}{cccccccccc} 
Case & $\begin{array}{c}\text { Case } \\
\text { start }\end{array}$ & $\begin{array}{c}\text { Case } \\
\text { end }\end{array}$ & SS start & SS end & $\begin{array}{c}\text { Solvent } \\
\text { flow } \\
\text { ton/h }\end{array}$ & $\begin{array}{c}\text { Stripper } \\
\text { pressure } \\
\text { barg }\end{array}$ & $\begin{array}{c}\mathrm{CO}_{2} \\
\text { capture } \\
\%\end{array}$ & $\begin{array}{c}\text { Inlet gas CO } \\
\text { concentration } \\
\text { vol\% dry }\end{array}$ & $\begin{array}{c}\mathrm{LVC}^{2} \\
\text { pressure } \\
\text { barg }\end{array}$ \\
\hline 1A-1 & $8 / 616: 30$ & $9 / 611: 55$ & $9 / 608: 25$ & $9 / 611: 55$ & 120 & 0.98 & 91 & 13.5 & N/A \\
1A-2 & $11 / 609: 30$ & $11 / 613: 25$ & $11 / 611: 35$ & $11 / 612: 45$ & 121 & 0.98 & 89 & 13.5 & N/A \\
1B & $9 / 612: 00$ & $10 / 611: 55$ & $10 / 607: 40$ & $10 / 611: 55$ & 161 & 0.98 & 89 & 13.7 & N/A \\
1C & $10 / 612: 00$ & $11 / 609: 25$ & $11 / 606: 30$ & $11 / 609: 25$ & 201 & 0.98 & 90 & 13.6 & N/A \\
1D & $16 / 610: 00$ & $16 / 620: 55$ & $16 / 615: 45$ & $16 / 619: 35$ & 201 & 0.98 & 80 & 13.7 & N/A \\
\hline 1E & $16 / 621: 00$ & $17 / 607: 45$ & $17 / 601: 30$ & $17 / 606: 40$ & 200 & 0.84 & 90 & 13.5 & N/A \\
1F & $15 / 623: 20$ & $16 / 609: 55$ & $16 / 607: 10$ & $16 / 609: 20$ & 201 & 0.98 & 90 & 11 & N/A \\
\hline 2A & $12 / 614: 30$ & $12 / 617: 10$ & $12 / 616: 20$ & $12 / 617: 10$ & 120 & 0.98 & 90 & 14 & 0.05 \\
2B & $12 / 617: 15$ & $13 / 608: 55$ & $13 / 600: 35$ & $13 / 608: 55$ & 166 & 0.98 & 90 & 13.7 & 0.05 \\
2C-1 & $13 / 609: 00$ & $13 / 619: 25$ & $13 / 612: 50$ & $13 / 615: 20$ & 201 & 0.98 & 88 & 13.7 & 0.05 \\
\hline 2C-2 & $14 / 603: 30$ & $14 / 610: 10$ & $14 / 607: 05$ & $14 / 609: 10$ & 201 & 0.98 & 89 & 13.8 & 0.2 \\
2C-3 & $13 / 619: 30$ & $14 / 603: 25$ & $14 / 601: 35$ & $14 / 603: 25$ & 201 & 0.98 & 90 & 13.7 & -0.01 \\
\hline 2D-1 & $14 / 617: 00$ & $14 / 623: 55$ & $14 / 620: 50$ & $14 / 622: 55$ & 202 & 0.98 & 80 & 13.9 & 0.04 \\
2D-2 & $14 / 610: 15$ & $14 / 616: 55$ & $14 / 613: 20$ & $14 / 616: 35$ & 202 & 0.98 & 81 & 13.7 & 0.2 \\
\hline 2E & $15 / 600: 00$ & $15 / 608: 10$ & $15 / 603: 45$ & $15 / 606: 30$ & 201 & 0.84 & 90 & 13.6 & 0.05 \\
2F & $15 / 611: 30$ & $15 / 623: 10$ & $15 / 615: 15$ & $15 / 618: 25$ & 202 & 0.98 & 90 & 11.1 & 0.04 \\
\hline
\end{tabular}

SS time-intervals were chosen manually based on all campaign process variables showing "flat line" behaviour. The timing of the steady state was chosen in order to have as many process variables acceptably constant over the SS period. The SS interval is usually significantly shorter than the case interval and it is typically just before the end of the case period, where steady state would be expected. This is shown in Figure 3 to Figure 6. Especially Figure 5 and Figure 6 indicate why the intervals where chosen this way. In the evaluation of SS all measured variables where analysed, not only the ones illustrated in the figures below.

Figure 3 shows that solvent flow was maintained at a very steady level throughout each case, even though there are some spikes and smaller deviations. The same type of steady conditions are exemplified by the temperatures around the lean/rich heat exchanger in Figure 4.

More variability is however seen in other process variables, such as the $\mathrm{CO}_{2}$ capture rate presented in Figure 5. Here a noticeable fluctuation is observed in between cases. Thus, the SS values have an amount of variability. These uncertainties are presented in the Data in Brief [reference to DIB] as standard deviations. Calculated standard deviations are based on averaged raw data over five-minute intervals.

The inlet process conditions for the plant were acceptably steady. This is exemplified in Figure 6 showing the dry 
$\mathrm{CO}_{2}$ content of the absorber inlet flue gas. The fluctuation typically observed before SS is mainly due to the accuracy of the gas flow control of recycled $\mathrm{CO}_{2}$.

Column temperature profiles are discussed in Appendix 1 and dataset is presented in Data in Brief [reference to DIB].

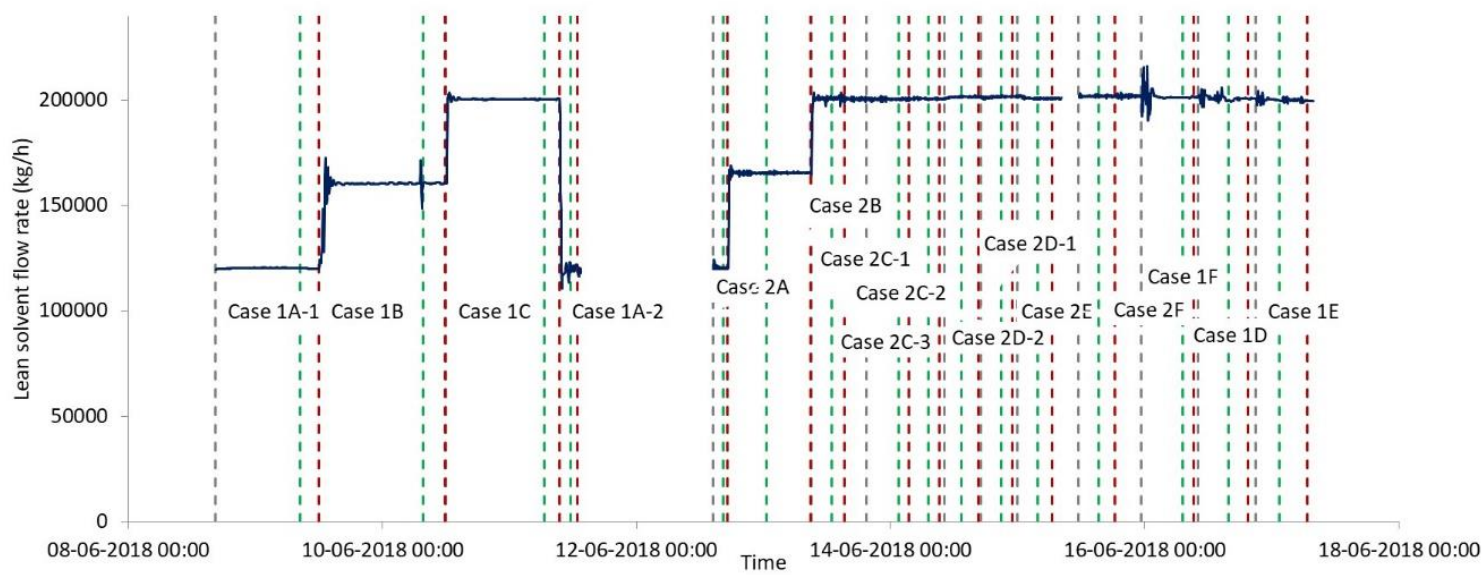

Figure 3. Overview of solvent flow rate during the complete LVC campaign, showing steady state case periods in between green and red dotted lines. Grey dotted line indicate change to new cases.

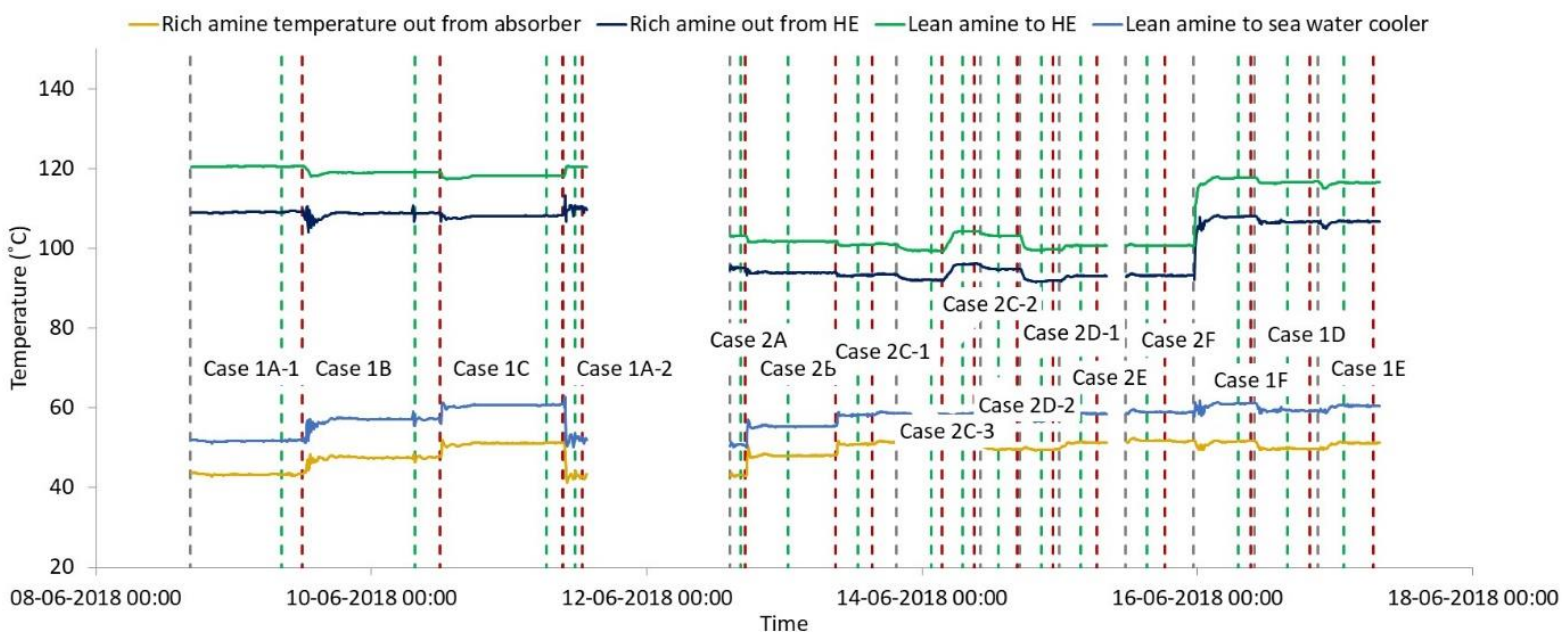

Figure 4. Overview of inlet and outlet solvent temperatures around the lean/rich cross heat exchanger during the complete LVC campaign. Steady state case periods are defined in between green and red dotted lines. Grey dotted line indicate change to new cases. 


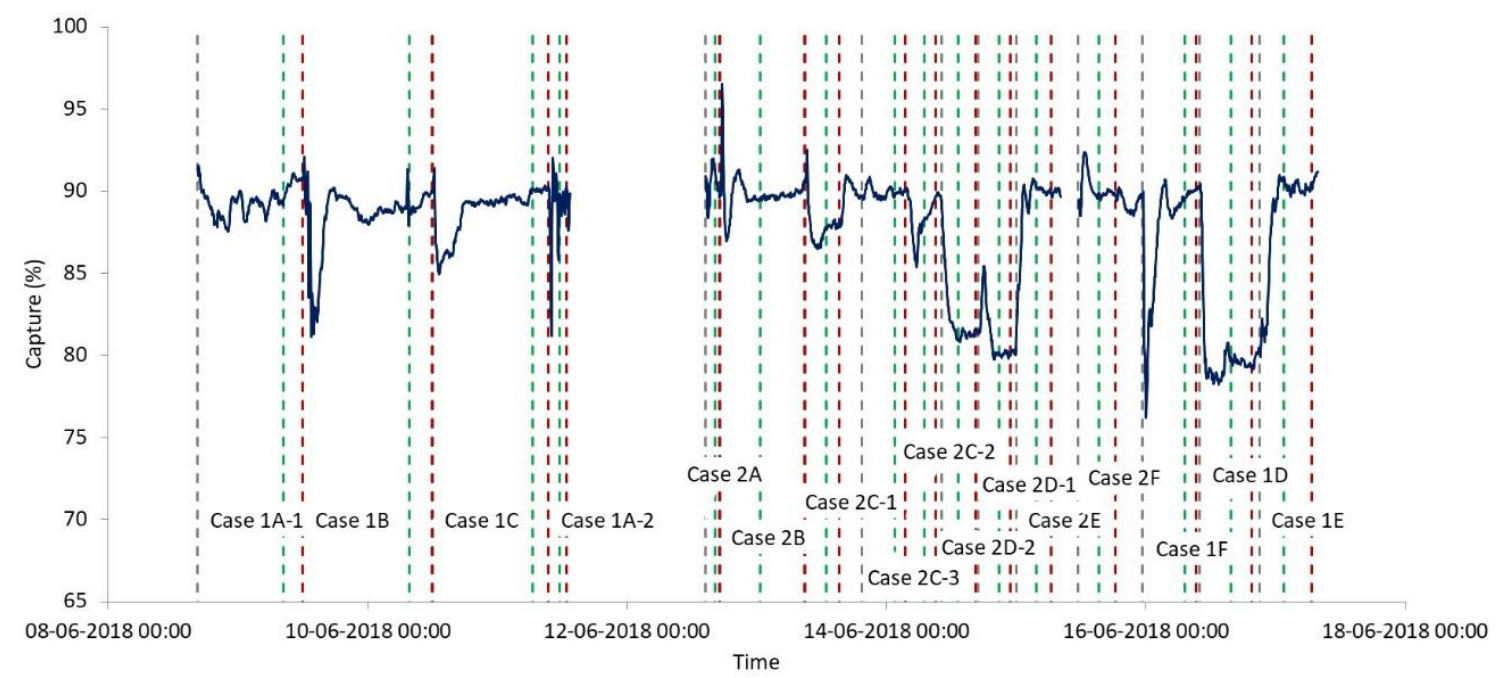

Figure 5. Overview of complete LVC campaign, showing $\mathrm{CO}_{2}$ capture rate. Steady state case periods are defined in between green and red dotted lines. Grey dotted line indicate change to new cases.

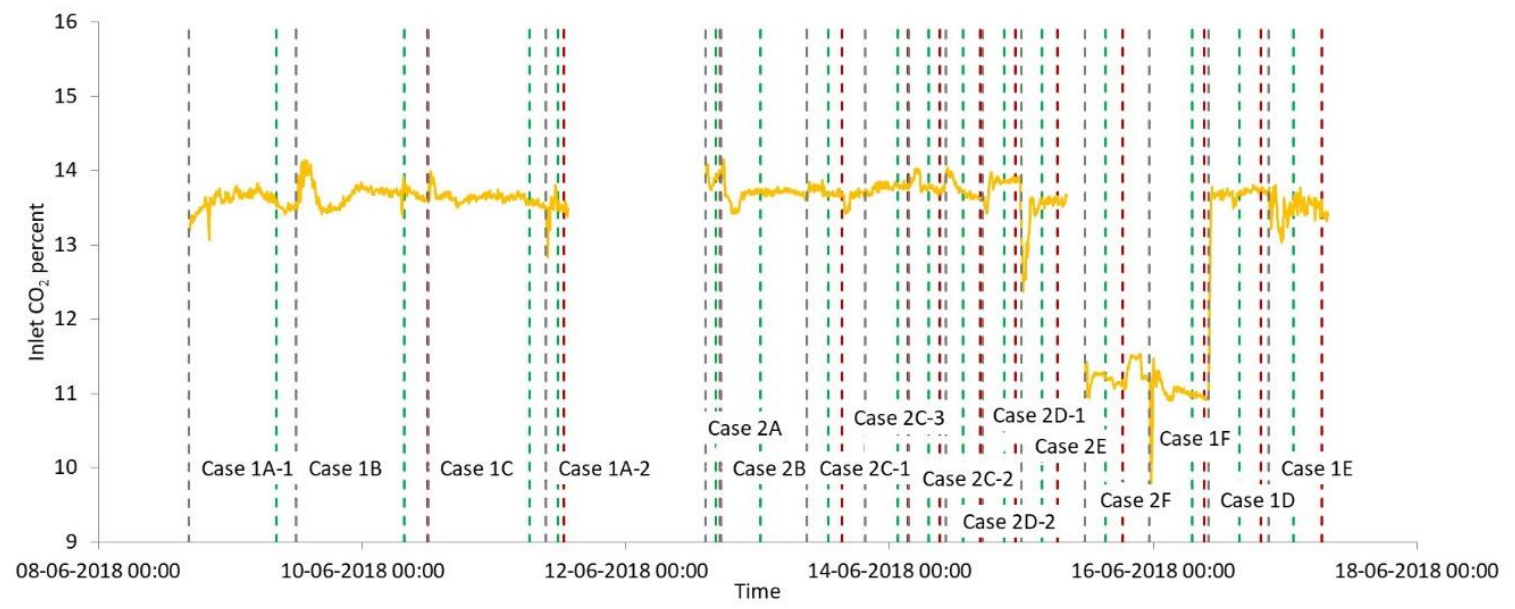

Figure 6. Overview of complete LVC campaign, showing $\mathrm{CO}_{2}$ dry vol\% in absorber feed gas. Steady state case periods are defined in between green and red dotted lines. Grey dotted line indicate change to new cases.

\subsection{Energy consumption and LVC performance}

The specific reboiler duty determined in both the BASE cases and the LVC cases is presented in Figure 7. It is in line with expected values from the literature [3], [5], [6]. From previous TCM baseline campaigns thermal energy consumption is expected to be approximately $3.6 \mathrm{MJ} / \mathrm{kg} \mathrm{CO} 2$ without LVC. The SRD is calculated based on the gas phase mass balance around the absorber and the steam consumption in the reboiler. The reboiler energy consumption is calculated based on an enthalpy balance for super-heated steam and sub-cooled condensate in and out of the reboiler.

Figure 7 shows that there is a clear reduction of SRD, in the order of $23 \%$, for all solvent flowrates when LVC is operated. The LVC performs as observed in the CESAR campaigns [4]. An interesting note is that the TCM LVC campaign was operated with some anti-surging in the compressor. Therefore, the LVC performance could have been even better if the LVC operation had been optimal in regards to anti-surge. For the tested solvent flow range the SRD steadily increases as a function of solvent flow which indicates that low solvent flow is preferable. The typical tendency of SRD as a function of solvent flow would show a minimum SRD at optimal solvent flow, giving a characteristic "u-curve" trend. This behaviour is not clearly observed in the present results, even though a flat u-curve 
can be seen, with a possible minimum at even lower flow rates than $120000 \mathrm{~kg} / \mathrm{h}$. The optimum solvent flow cannot be determined accurately from these results.

The reproducibility of the results is depicted in Figure 7, exemplified at $120000 \mathrm{~kg} / \mathrm{h}$ for case $1 \mathrm{~A}-1$ and $1 \mathrm{~A}-2$.This is shown by circle "A". The variability of SRD in case 1A-1 and 1A-2 reveals that the repeatability of the reboiler duty is $1 \%(0.04 \mathrm{GJ} /$ ton out of $3.70 \mathrm{GJ} /$ ton $)$. The SS data presented in table 4 specifies that the accuracy of measurement around the reboiler is in the order of $0.5 \%$. Therefore, the $1 \%$ could originate from other factors like fluctuations in flow, temperatures, pressures, etc.

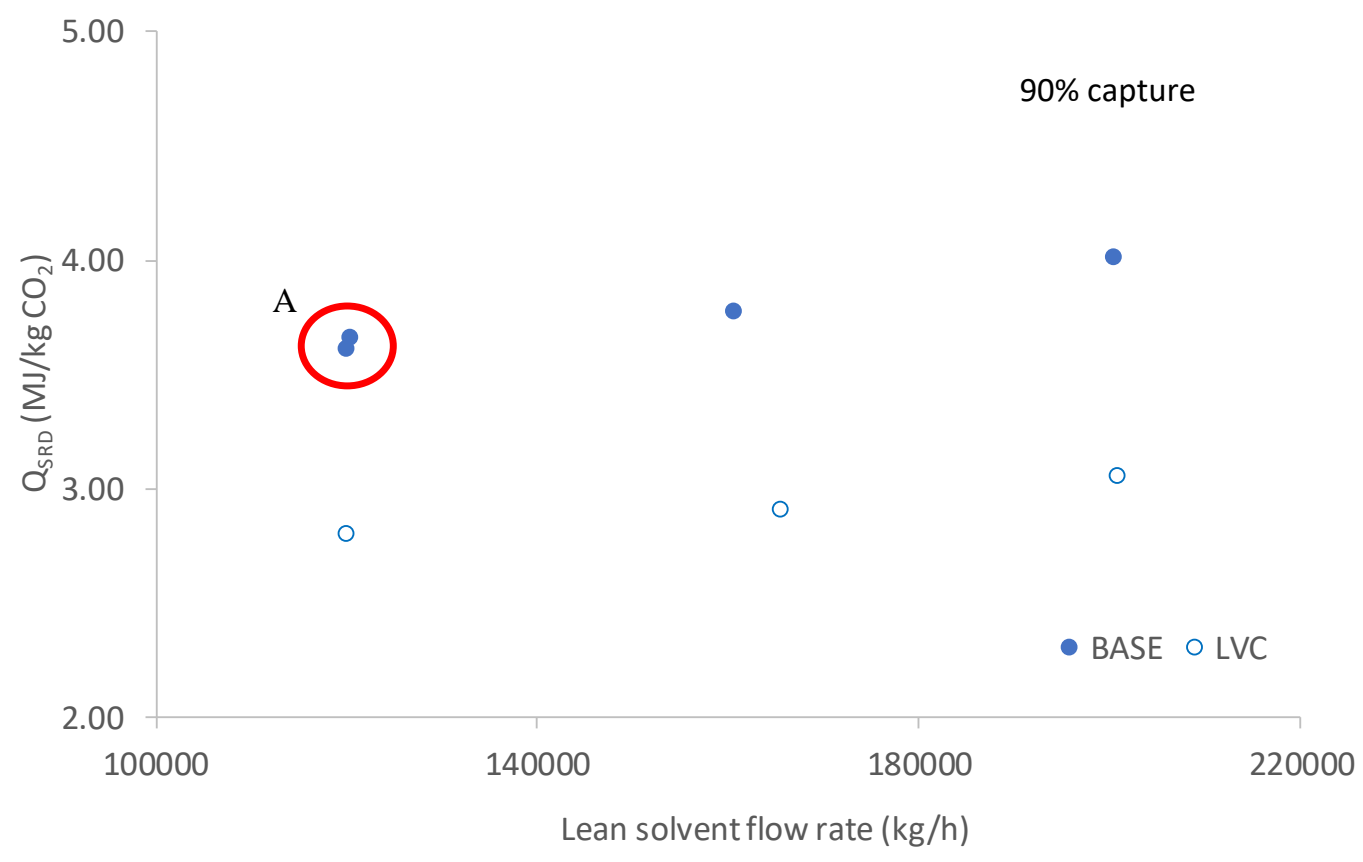

Figure 7. SRD as a function of solvent flow rate. 


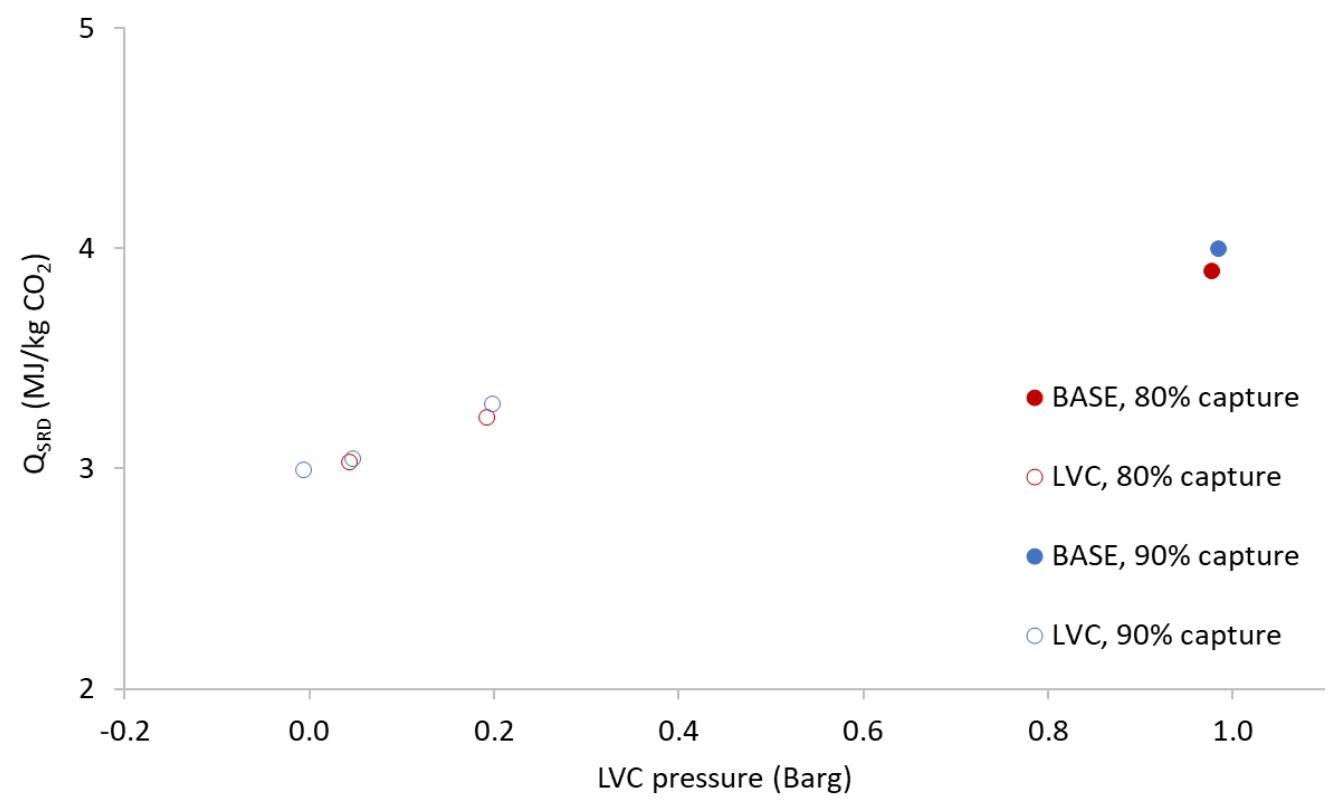

Figure 8. SRD as a function of LVC pressure at a solvent flow rate of $200000 \mathrm{~kg} / \mathrm{h}$.

Figure 8 shows the SRD as function of LVC pressure. There is a clear linear trend of decreasing SRD with LVC flash vessel pressure. This should be seen in comparison to the LVC power consumption which has a similar linear trend, as shown in Figure 9. SRD can be reduced with the expense of more power for the LVC. This observation corresponds to previous results from CESAR [4]. The energy saving from using $80 \%$ capture to $90 \%$ capture is a maximum of $3 \%$ for the cases when LVC is used.

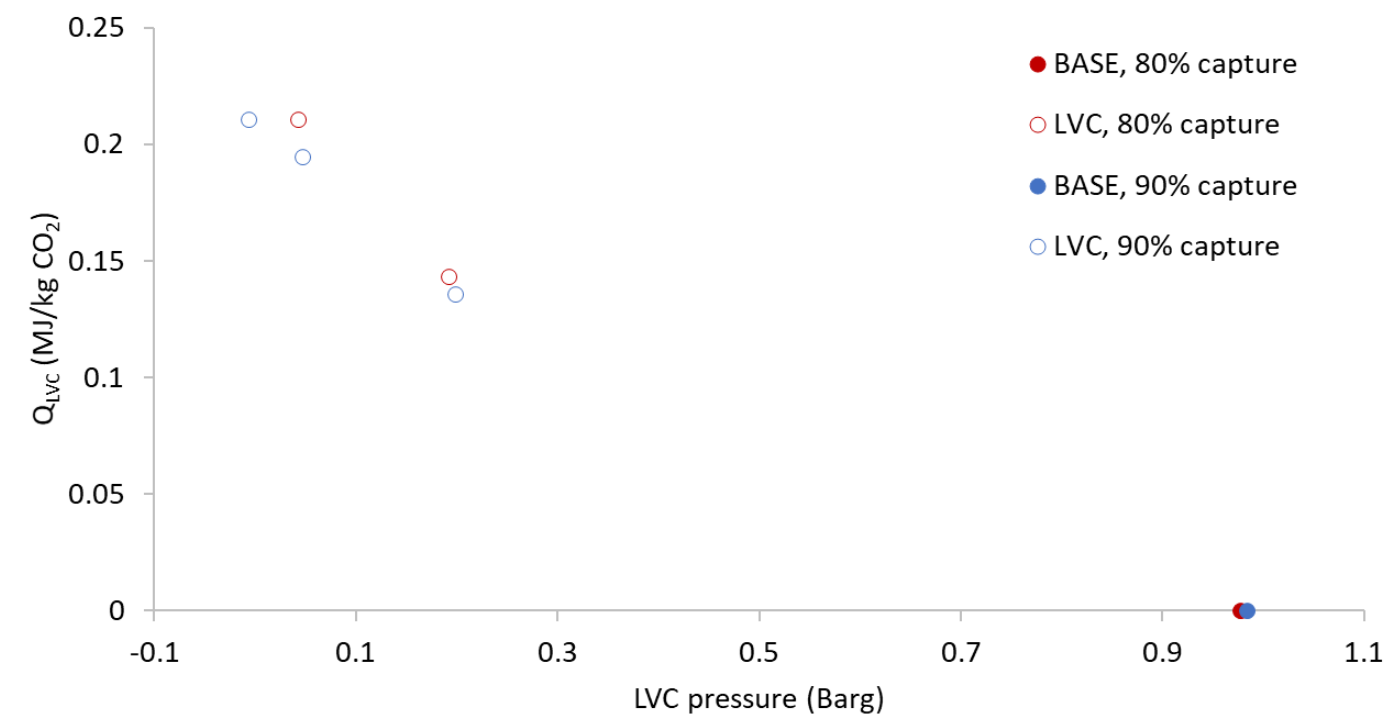

Figure 9. LVC power consumption as a function of LVC pressure at a solvent flow rate of 200 ton/h. 


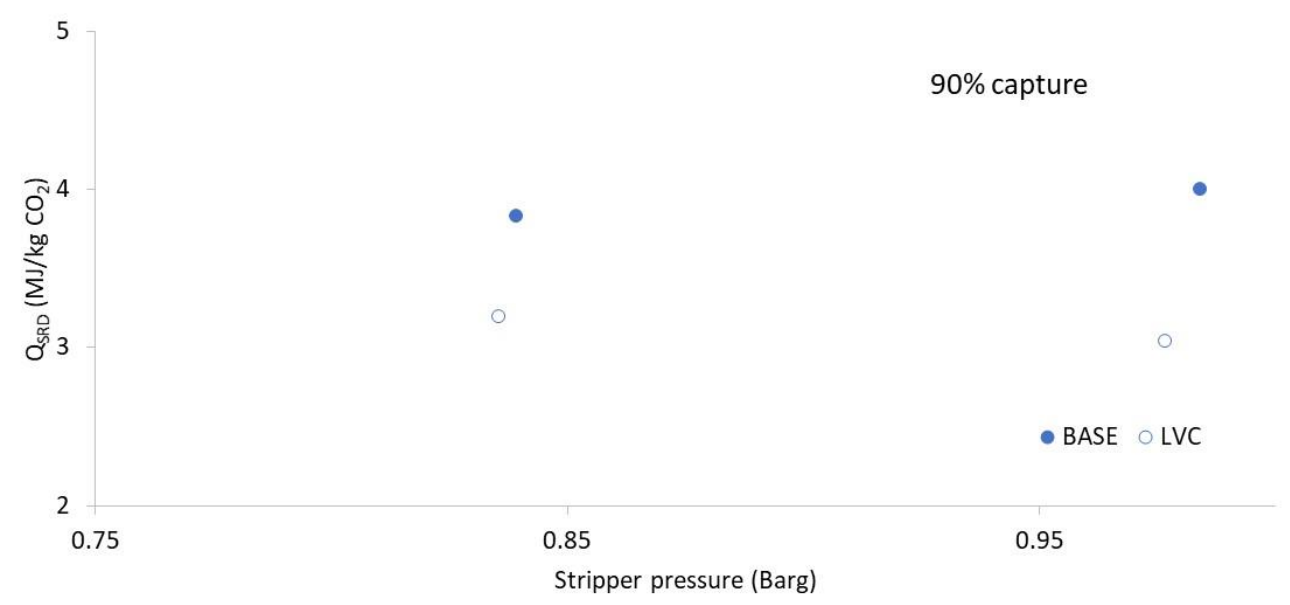

Figure 10. SRD as a function of stripper pressure.

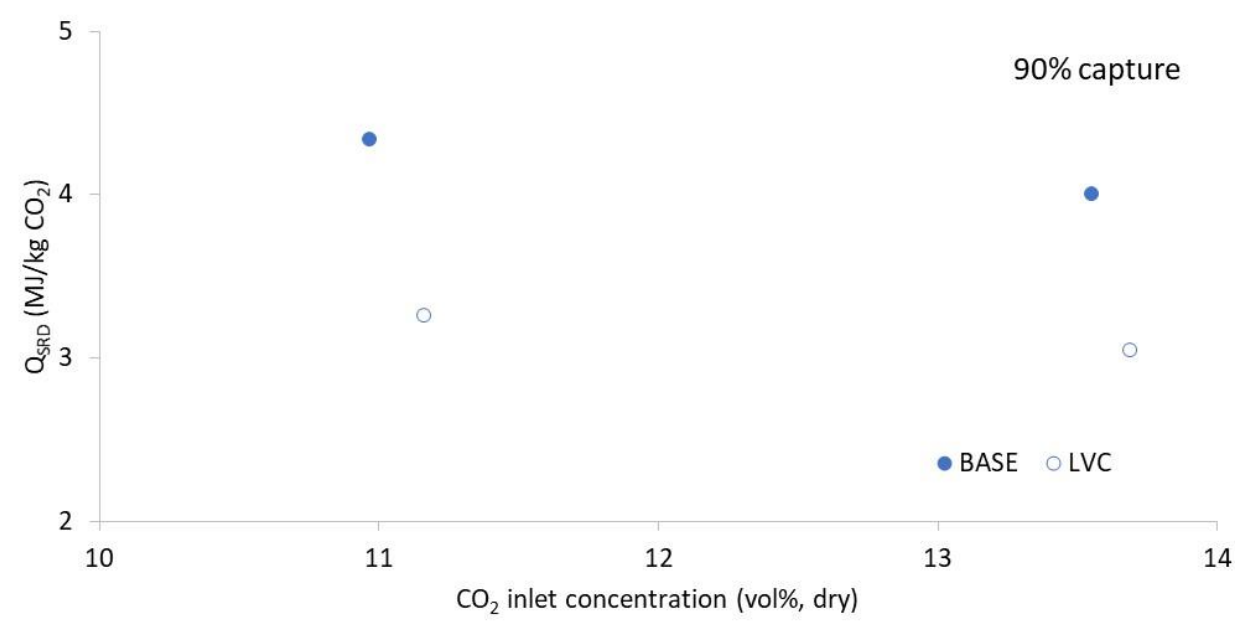

Figure 11. SRD as a function of inlet flue-gas $\mathrm{CO}_{2}$ concentration (dry basis).

The impact of stripper pressure is presented in Figure 10. The figure indicates that there might be a tendency towards lower SRD for higher stripper pressures for the LVC cases. The LVC power consumption increases 0.04GJ electric/ton while the SRD, which exclude LVC power, decreases $0.16 \mathrm{GJ} / \mathrm{ton}$. At the same time, the opposite results are seen for the base cases. This means that there is a noticeable and clear positive benefit of using LVC at increased stripper pressure. The LVC cases will consume more power at high pressure, since the LVC will experience a large $\Delta \mathrm{P}$.

Figure 11 shows the $\mathrm{SRD}$ as a function of inlet flue gas $\mathrm{CO}_{2}$ concentration (dry basis). The clear trend shows that low inlet flue gas $\mathrm{CO}_{2}$ concentration gives a significantly higher SRD; here it is above 4GJ/ton for the BASE $11 \%$ $\mathrm{CO}_{2}$ case. 


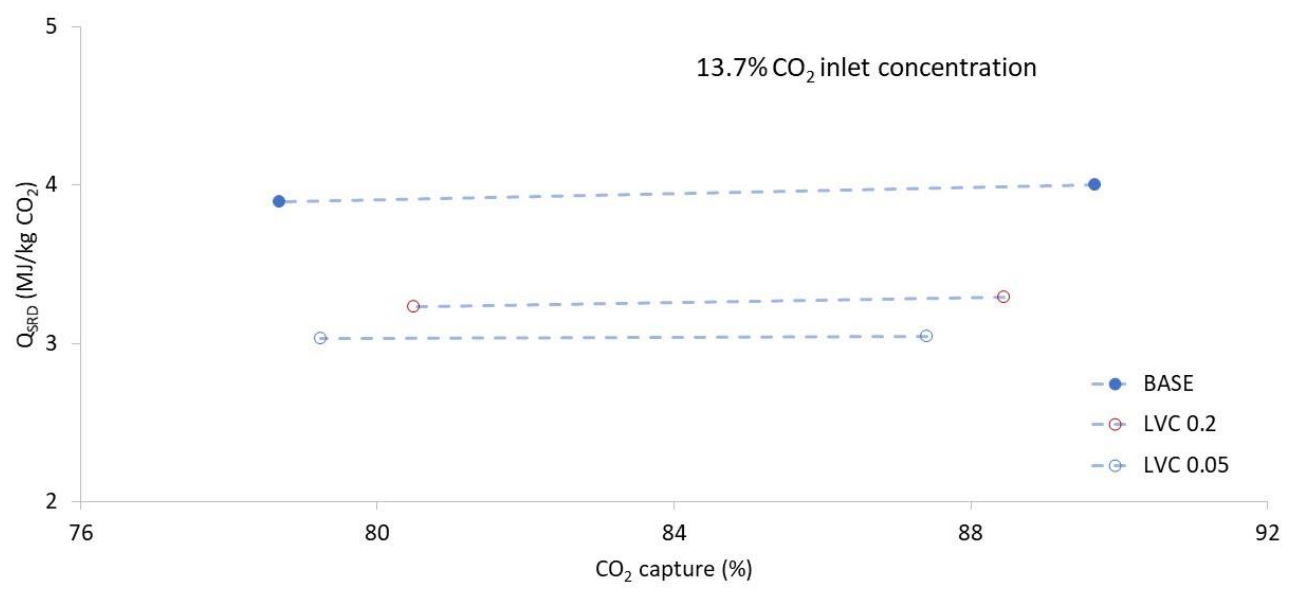

Figure 12. SRD as a function of capture percent.

Figure 12 shows the SRD as function of $\mathrm{CO}_{2}$ capture rate, in the range of 80 to $90 \%$ capture. The trend in data going from 80 to $90 \%$ seem similar in all cases from BASE to the low-pressure 0.05 barg LVC case. The higher the capture rate the more energy would be required, which is a quite an expected result [12]. The additional energy required, is on the other hand not significant. There is a clear effect of the LVC.

It should be noted that all SRD results presented in the figures above only include energy consumed in the reboiler $\left(\mathrm{Q}_{\mathrm{SRD}}\right)$ and not electric energy for the $\mathrm{LVC}\left(\mathrm{Q}_{\mathrm{LVC}}\right)$. This approach is used due to the fact that the electrical power used in the LVC and thermal power used for SRD are not directly comparable.

The specific energy consumption of the LVC is presented in Table 3, with typical values in the range of $0.1-0.2$ GJ electric/ton $\mathrm{CO}_{2}$. This corresponds to about $5 \%$ of the total energy consumed in the reboiler, not taking thermal efficiency into account, $\left(0.1\right.$ to $0.2 \mathrm{GJ}$ electric/ton $\mathrm{CO}_{2}$ out of approximately $3.7 \mathrm{GJ} /$ ton $\left.\mathrm{CO}_{2}\right)$. In the work by Sanchez Fernandez et al. [1] a conversion factor of 0.23 was used, which accounts for the loss of turbine power due to steam extraction from the reboiler. When applying the conversion factor of 0.23 on the cases presented in this work, the LVC shows little to no reduction of the overall energy consumption. It should however be noticed that the present LVC results were influenced by the use of anti-surge which could have resulted in higher LVC energy consumption than expected. The results are therefore somewhat inconclusive towards the energy consumption and it is not possible to give general recommendations based on the present energy analysis.

To get a deeper understanding of the LVC performance impact on the energy consumption it would be important to eliminate the use of anti-surge. Additionally, there is a possibility to apply a green power source like hydro or wind turbine for the LVC and thereby prevent the need for extraction of power from the steam turbine. In such cases, the steam conversion factor would not be relevant. Thus, the actual turbine efficiency could be very different in future LVC applications. 
Table 3: Overview of main process variables for the 16 test cases, $1 \mathrm{~A}$ to $2 \mathrm{~F}$.

\begin{tabular}{|c|c|c|c|c|c|c|c|c|c|c|c|c|c|c|c|c|c|c|}
\hline Description & Unit & & $\begin{array}{l}\text { Case } \\
1 \mathrm{~A}-1\end{array}$ & $\begin{array}{r}\text { Case } \\
1 \mathrm{~B}\end{array}$ & $\begin{array}{r}\text { Case } \\
1 \mathrm{C}\end{array}$ & $\begin{array}{l}\text { Case } \\
1 \mathrm{~A}-2\end{array}$ & $\begin{array}{r}\text { Case } \\
\text { 1D }\end{array}$ & $\begin{array}{r}\text { Case } \\
1 \mathrm{E}\end{array}$ & $\begin{array}{r}\text { Case } \\
1 \mathrm{~F}\end{array}$ & $\begin{array}{r}\text { Case } \\
2 \mathrm{~A}\end{array}$ & $\begin{array}{r}\text { Case } \\
2 \mathrm{~B}\end{array}$ & $\begin{array}{l}\text { Case } \\
2 \mathrm{C}-1\end{array}$ & $\begin{array}{l}\text { Case } \\
2 \mathrm{C}-2\end{array}$ & $\begin{array}{l}\text { Case } \\
2 \mathrm{C}-3\end{array}$ & $\begin{array}{l}\text { Case } \\
\text { 2D-1 }\end{array}$ & $\begin{array}{l}\text { Case } \\
\text { 2D-2 }\end{array}$ & $\begin{array}{r}\text { Case } \\
2 \mathrm{E}\end{array}$ & $\begin{array}{r}\text { Case } \\
2 \mathrm{~F}\end{array}$ \\
\hline \multirow{2}{*}{$\begin{array}{l}\text { CHP Flue gas flow rate into } \\
\text { absorber }\end{array}$} & $\mathrm{Sm}^{3} / \mathrm{h}$ & mean & 34985 & 34983 & 34996 & 34997 & 34985 & 34984 & 34995 & 34996 & 34986 & 34988 & 34989 & 34995 & 35001 & 34991 & 34996 & 34991 \\
\hline & & stdev & 60 & 45 & 50 & 61 & 63 & 60 & 63 & 63 & 60 & 61 & 42 & 53 & 65 & 47 & 60 & 47 \\
\hline \multirow{2}{*}{$\begin{array}{l}\mathrm{CO}_{2} \text { concentration into } \\
\text { absorber }\end{array}$} & vol\%, dry & mean & 13.5 & 13.7 & 13.6 & 13.5 & 13.7 & 13.5 & 11.0 & 14.0 & 13.7 & 13.7 & 13.8 & 13.8 & 13.9 & 13.7 & 13.6 & 11.2 \\
\hline & & stdev & 0.04 & 0.06 & 0.04 & 0.05 & 0.03 & 0.09 & 0.02 & 0.03 & 0.03 & 0.03 & 0.04 & 0.03 & 0.02 & 0.03 & 0.04 & 0.04 \\
\hline \multirow[t]{2}{*}{ Lean solvent flow rate } & $\mathrm{t} / \mathrm{h}$ & mean & 120.1 & 160.7 & 200.5 & 120.5 & 200.6 & 200.1 & 201.3 & 120.2 & 165.6 & 200.9 & 200.8 & 200.6 & 201.7 & 201.7 & 200.9 & 202.1 \\
\hline & & stdev & 0.15 & 0.24 & 0.18 & 0.12 & 0.54 & 0.73 & 0.24 & 0.35 & 0.33 & 1.2 & 0.27 & 0.52 & 0.25 & 0.27 & 0.27 & 0.36 \\
\hline \multirow[t]{2}{*}{ Pressure in stripper bottom } & barg & mean & 0.98 & 0.98 & 0.98 & 0.98 & 0.98 & 0.84 & 0.98 & 0.98 & 0.98 & 0.98 & 0.99 & 0.98 & 0.98 & 0.98 & 0.84 & 0.98 \\
\hline & & stdev & 0.001 & 0.002 & 0.001 & 0.001 & 0.001 & 0.002 & 0.001 & 0.001 & 0.001 & 0.002 & 0.001 & 0.001 & 0.001 & 0.001 & 0.001 & 0.001 \\
\hline \multirow{2}{*}{$\begin{array}{l}\text { Reboiler outlet pressure, } \\
\text { steam }\end{array}$} & barg & mean & 2.75 & 2.76 & 2.91 & 2.70 & 2.30 & 2.48 & 2.37 & 2.33 & 2.27 & 2.12 & 2.25 & 2.16 & 1.92 & 2.00 & 2.03 & 1.97 \\
\hline & & stdev & 0.009 & 0.013 & 0.010 & 0.011 & 0.014 & 0.015 & 0.007 & 0.007 & 0.007 & 0.008 & 0.013 & 0.007 & 0.004 & 0.006 & 0.008 & 0.008 \\
\hline \multirow[t]{2}{*}{ LVC pressure } & barg & mean & 1.01 & 1.01 & 1.01 & 1.01 & 1.01 & 0.87 & 1.01 & 0.05 & 0.05 & 0.05 & 0.2 & -0.006 & 0.04 & 0.2 & 0.05 & 0.04 \\
\hline & & stdev & 0.001 & 0.001 & 0.001 & 0.003 & 0.002 & 0.001 & 0.001 & 0.001 & 0.002 & 0.002 & 0.001 & 0.001 & 0.001 & 0.001 & 0.001 & 0.002 \\
\hline \multirow[t]{2}{*}{ QSRD } & $\mathrm{MJ} / \mathrm{kg} \mathrm{CO} 2$ & mean & 3.60 & 3.77 & 4.00 & 3.66 & 3.90 & 3.83 & 4.34 & 2.79 & 2.90 & 3.04 & 3.29 & 3.00 & 3.03 & 3.23 & 3.20 & 3.26 \\
\hline & & stdev & 0.064 & 0.035 & 0.021 & 0.042 & 0.027 & 0.040 & 0.023 & 0.016 & 0.016 & 0.021 & 0.024 & 0.018 & 0.016 & 0.018 & 0.025 & 0.021 \\
\hline \multirow[t]{2}{*}{ QLVC } & $\begin{array}{r}\text { GJ } \\
\text { electric/ton }\end{array}$ & mean & 0.000 & 0.000 & 0.000 & 0.000 & 0.000 & 0.000 & 0.000 & 0.19 & 0.19 & 0.19 & 0.14 & 0.21 & 0.21 & 0.14 & 0.15 & 0.24 \\
\hline & & stdev & 0.0000 & 0.0000 & 0.0000 & 0.0000 & 0.0000 & 0.0000 & 0.0000 & 0.0008 & 0.0009 & 0.001 & 0.0006 & 0.0006 & 0.0008 & 0.0016 & 0.0008 & 0.0008 \\
\hline lean loading ${ }^{\mathrm{a}}$ & $\mathrm{mol} / \mathrm{mol}$ & & 0.215 & 0.265 & 0.290 & $-{ }^{b}$ & 0.318 & 0.273 & 0.292 & 0.201 & 0.266 & 0.284 & 0.280 & 0.285 & 0.318 & 0.318 & 0.288 & 0.301 \\
\hline rich loading ${ }^{a}$ & $\mathrm{~mol} / \mathrm{mol}$ & & 0.483 & 0.524 & 0.507 & $-{ }^{b}$ & 0.507 & 0.486 & 0.467 & 0.543 & 0.513 & 0.493 & 0.488 & 0.483 & 0.493 & 0.501 & 0.496 & 0.467 \\
\hline \multirow[t]{2}{*}{$\mathrm{CO}_{2}$ capture } & $\%$ & mean & 90.1 & 88.9 & 89.7 & 88.9 & 78.7 & 89.8 & 89.5 & 89.8 & 89.4 & 87.4 & 88.4 & 89.5 & 79.2 & 80.5 & 89.6 & 89.4 \\
\hline & & stdev & 0.39 & 0.48 & 0.11 & 0.63 & 0.21 & 0.28 & 0.16 & 0.38 & 0.27 & 0.16 & 0.50 & 0.10 & 0.12 & 0.022 & 0.17 & 0.16 \\
\hline
\end{tabular}

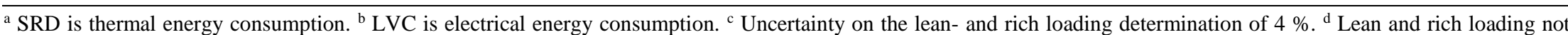
measured for case 1A-2. 


\subsection{Anti-surge valve}

The TCM LVC has a large compressor. For safety reasons it has a built-in anti-surge option which is used when flow to the compressor is below design flow. The control of the LVC automatically recycles gas in order to allow for correct compressor operation.

Compressor design specifications are provided in table 4 where mass flow into the LVC, inlet and outlet temperatures and pressure are found. The range of the operational parameters for the campaign are also included in the table. The LVC was designed to operate at conditions in the range 5677 to $11105 \mathrm{~kg} / \mathrm{h}$ with a desired design of $7025 \mathrm{~kg} / \mathrm{h}$. The inlet gas flow to the compressor during the campaign was between 6700 and $7400 \mathrm{~kg} / \mathrm{h}$, including anti-surge flow. The compressor maintains a steady inlet flow by controlling the anti-surge valve opening. The outlet from the compressor was 3600 to $5400 \mathrm{~kg} / \mathrm{h}$. Inlet and outlet flows are illustrated in Figure 13. Approximately 25$50 \%$ of gas was constantly recycled in the compressor. The anti-surge valve opening is linearly correlated with the percent gas recycling in the compressor, see Figure 14. Therefore anti-surge opening is linearly correlated with LVC energy consumption. The anti-surge is cooled by the lean solvent coming from the stripper. There is little to insignificant temperature increase between anti-surge cooler inlet and outlet on the cold side [reference to DIB]. Gas recycling may likely have contributed by up to $50 \%$ increase in LVC energy consumption.

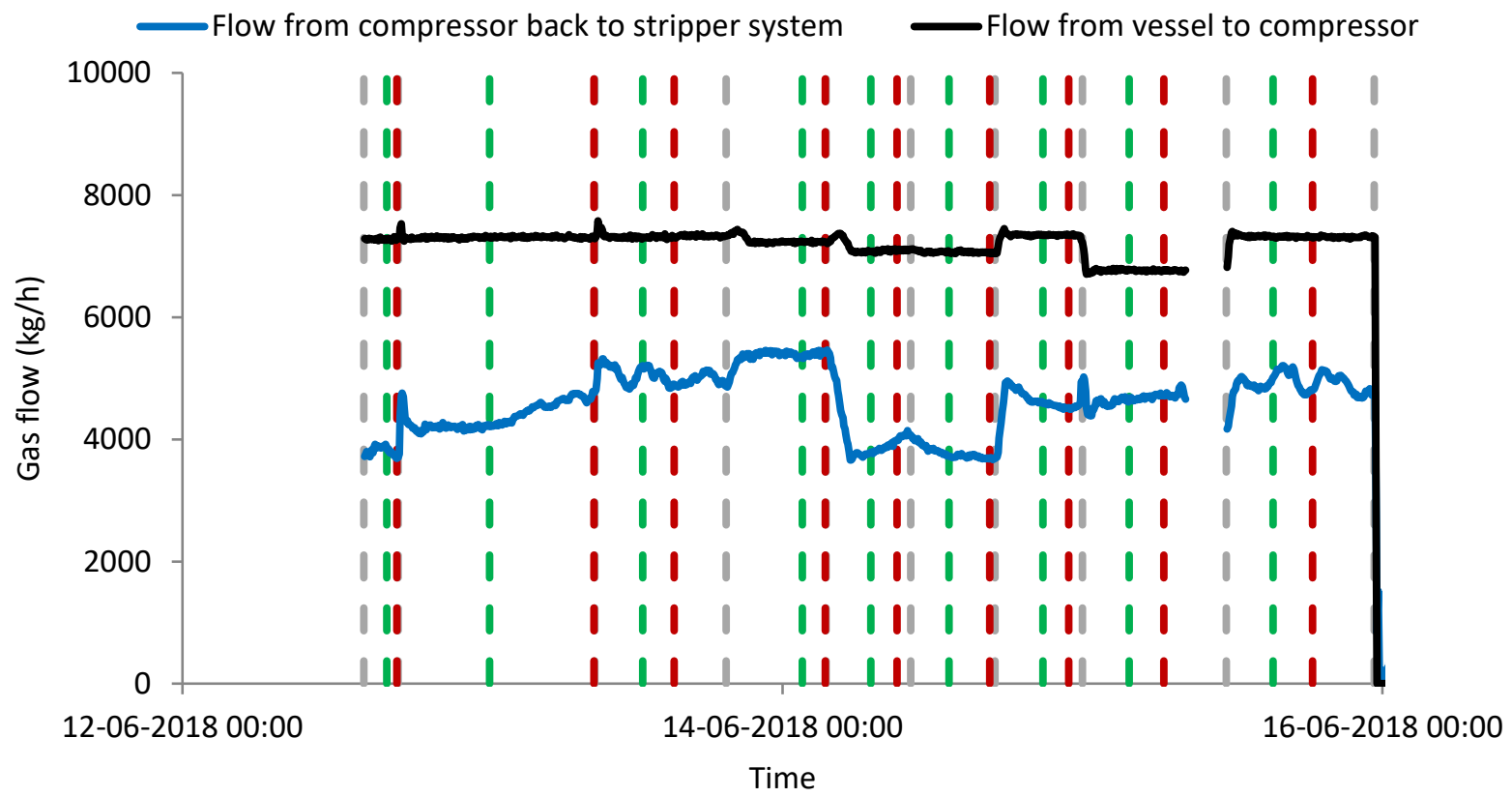

Figure 13. Flow from flash vessel to LVC, and flow from LVC to stripper as a function of time. 
Table 4. Compressor design specification.

\begin{tabular}{llllll}
\hline & Unit & Design & Low inlet & High inlet & Campaign \\
\hline Polytropic efficiency & $\%$ & 78.1 & 77.7 & 77.8 & \\
& \multicolumn{2}{c}{ Inlet conditions } \\
\hline Mass flow & $\mathrm{kg} / \mathrm{h}$ & 7025 & 5677 & 11105 & $6800-7400^{*}$ \\
Pressure & $\mathrm{Bara}$ & 0.95 & 0.7 & 2.1 & $0.87-1.1$ \\
Temperature & ${ }^{\circ} \mathrm{C}$ & 102 & 94.19 & 123.7 & $97-103$ \\
& \multicolumn{7}{c}{ Outlet conditions } \\
Pressure & Bara & 1.9 & 1.5 & 3.5 & $1.9-2.1$ \\
Temperature & ${ }^{\circ} \mathrm{C}$ & 189.4 & 190.2 & 189 & $171-198$ \\
\hline
\end{tabular}

*This flow includes anti-surge. The flow in/out of the LVC is 3600 to $5400 \mathrm{~kg} / \mathrm{h}$

The anti-surge valve opening is linearly correlated with solvent flow, see figure 15. A high flow results in less antisurge. The high solvent flow cases will give higher vaporization of both $\mathrm{CO}_{2}$ and water and therefore a lower antisurge valve opening. The increased vaporization from $120000 \mathrm{~kg} / \mathrm{h}$ to $200000 \mathrm{~kg} / \mathrm{h}$ (case $2 \mathrm{~A}$ and $2 \mathrm{C}-1$ ) is $33.9 \%$. A simple simulation confirms an expected increase in vaporization of $34.4 \%$. A high solvent flow of $200000 \mathrm{~kg} / \mathrm{h}$ was applied for the cases $2 \mathrm{C}-1$ to $2 \mathrm{~F}$ to reach a low anti-surge flow, even though this may not have been the optimal flow. The flow from the LVC into the stripper was typically 3600 to $5400 \mathrm{~kg} / \mathrm{h}$. It is linearly correlated with the solvent flow, see Figure 16. It should be noted that this flow is quite significant compared to the $\mathrm{CO}_{2}$ flow out of the stripper, which for all $90 \%$ capture cases is approximately $7500 \mathrm{~kg} / \mathrm{h}$ and for the $80 \%$ capture cases $6600 \mathrm{~kg} / \mathrm{h} \mathrm{CO}_{2}$.

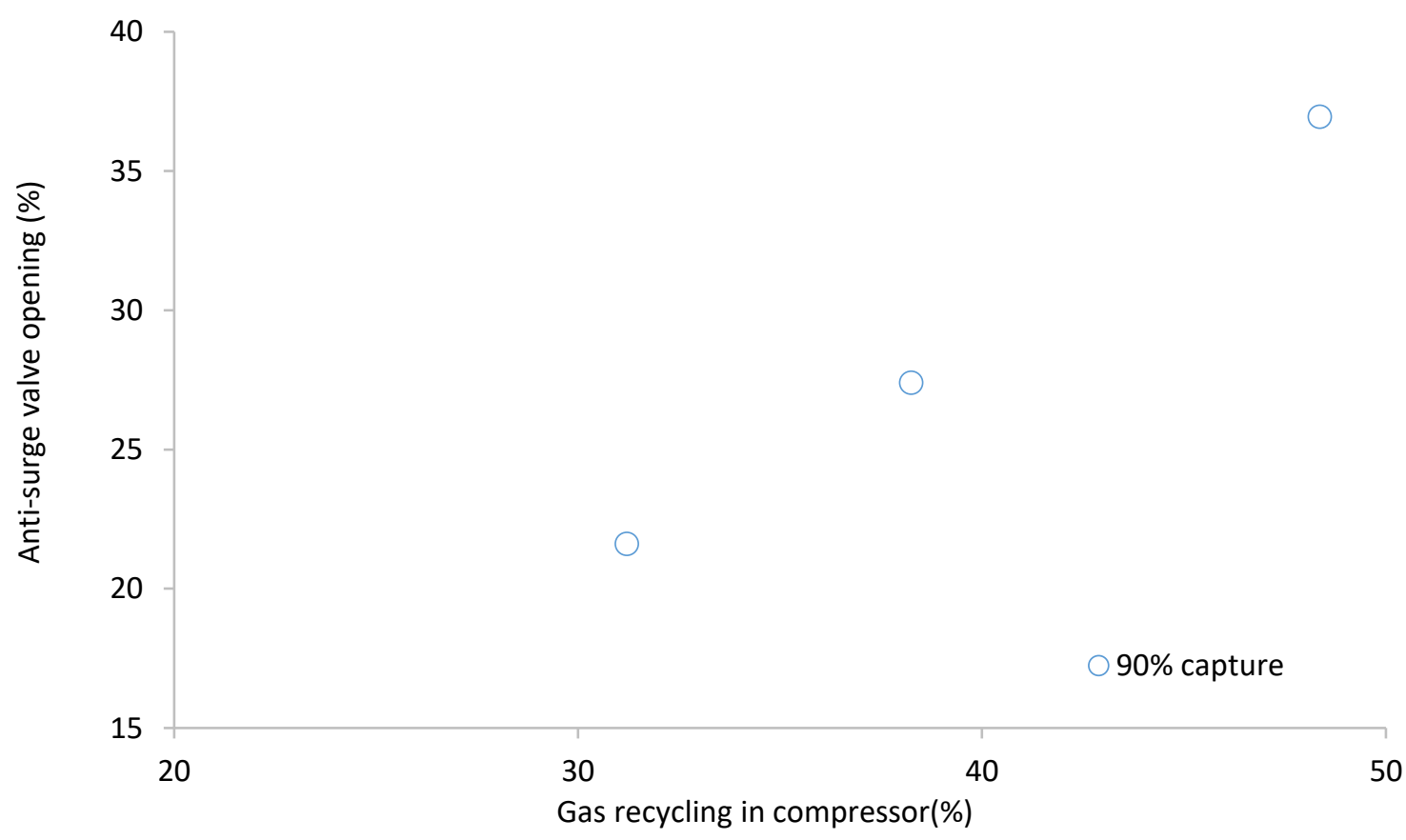

Figure 14. Anti-surge valve opening as a function of gas recycling in compressor. 


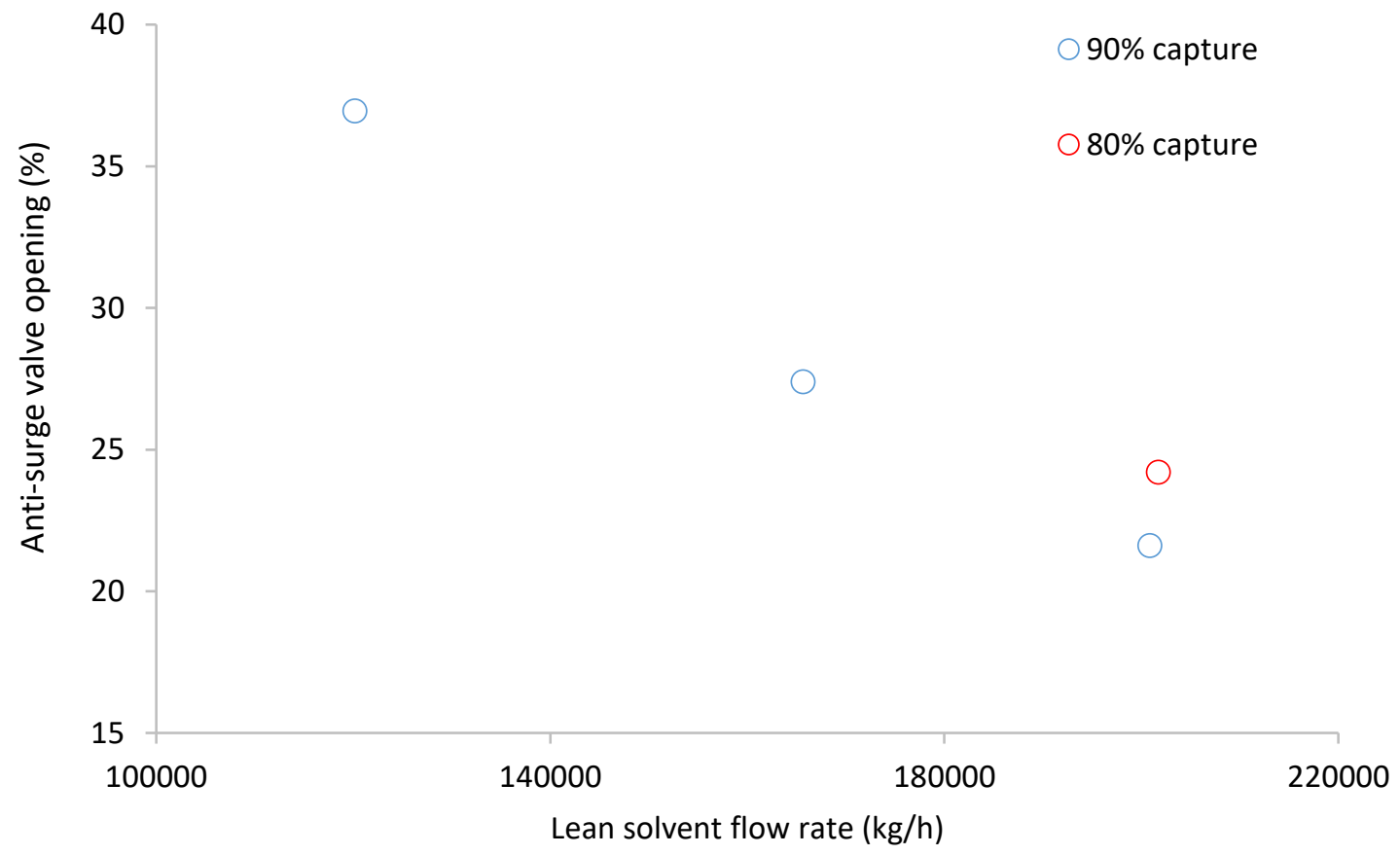

Figure 15. Anti-surge valve opening as a function of solvent flow rate.

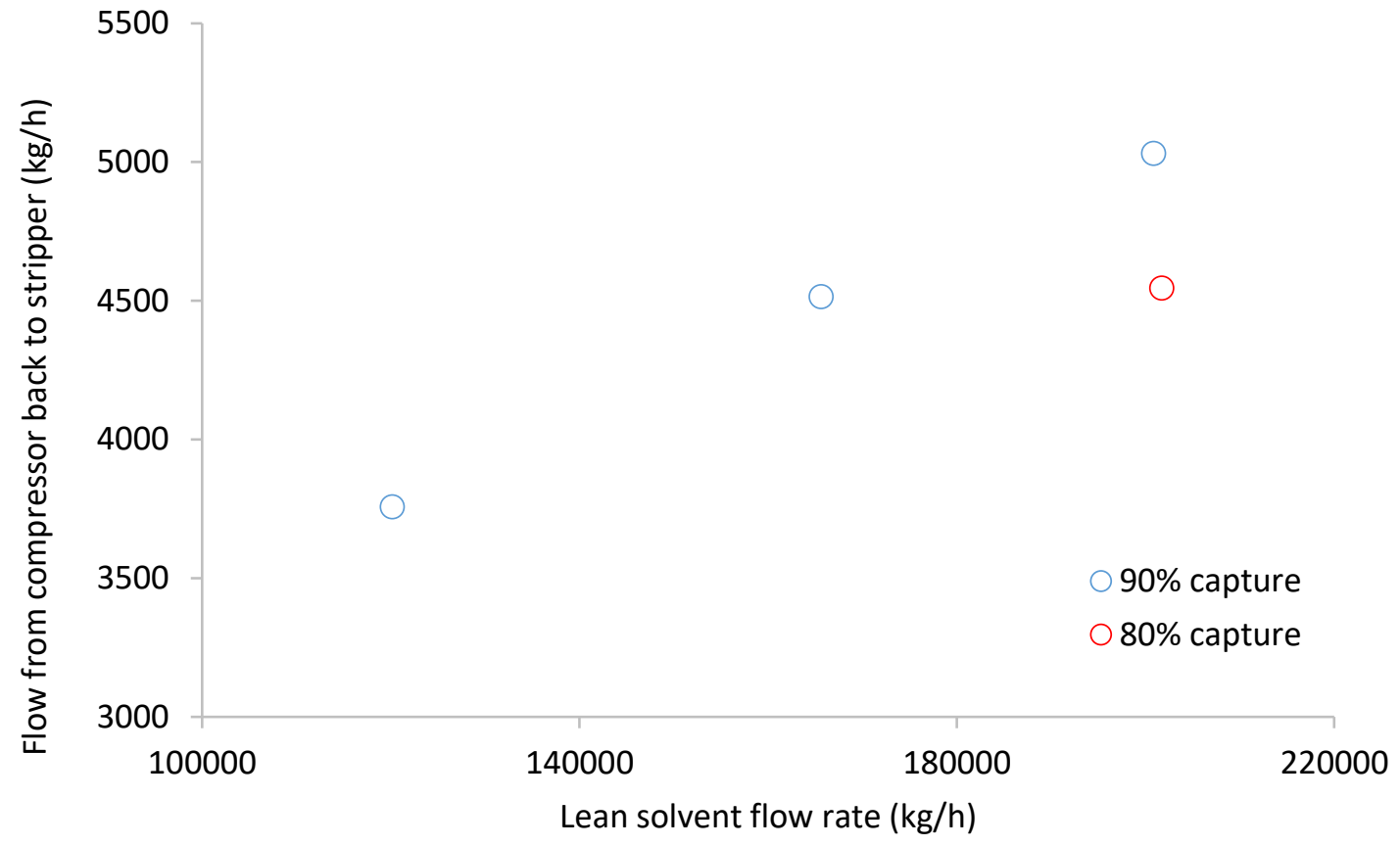

Figure 16. Flow from compressor back to stripper (equivalent to flow into the LVC - excluding anti-surge) as a function of solvent flow rate. 


\subsection{Consequences of LVC temperature}

The typical lean temperature from the stripper without $\mathrm{LVC}$ is in the order of $120{ }^{\circ} \mathrm{C}$. The low pressure flash in the LVC causes the lean temperature to decrease quite significantly, see Figure 17. The reason is that vaporization in the flash requires energy and reduces the temperature. There is a linear dependency between the hot lean amine temperature and the LVC pressure, as seen in Figure 17. The cooling observed is caused by flashing in the LVC. This temperature impacts the main cross-heat exchanger to give a lower rich solvent stripper inlet temperature and results in a lower stripper outlet gas temperature as illustrated in figure 18. The outcome is less cooling water demand in the overhead condenser and reduced water reflux, which is beneficial to the energy consumption of the capture plant.

The flow from the compressor to the stripper is linearly correlated with the hot lean amine temperature, as depicted in figure 19. Lower LVC pressure is increasing the flow from the compressor to the stripper and it is also lowering the hot lean amine temperature significantly. This is expected, as more flashing causes more vaporization and lower temperature.

Comparing $80 \%$ and $90 \%$ capture cases show an interesting behaviour: The capture percent was controlled by the steam use in the reboiler and eventually lean loading. The case with $80 \%$ capture results in less vaporization and a higher anti-surge valve opening than the case with $90 \%$ capture at $200000 \mathrm{~kg} / \mathrm{h}$. The $80 \%$ capture case has higher lean loading. This would induce an expected higher $\mathrm{CO}_{2}$ flow and higher overall flow into the LVC. This is not observed, see figure 16. In the $80 \%$ case, the lean loading is higher but the temperature is lower for similar LVC pressures, see figure 19. This case is likely to give higher $\mathrm{CO}_{2}$ vaporization and less water vaporization. The water reduces more than the $\mathrm{CO}_{2}$ increases and the overall $\mathrm{LVC}$ vaporization is lower. This is confirmed by estimates using extended UNIQUAC calculations. Simulation show that vaporization has a composition of approximately $85 \mathrm{wt} \%$ water, $15 \mathrm{wt} \% \mathrm{CO}_{2}$, and $0.5 \mathrm{wt} \%$ MEA. Changing from $90 \%$ to $80 \%$ capture gives up to $35 \%$ more $\mathrm{CO}_{2}, 15 \%$ less water and 30\% less MEA vaporization in the LVC flash. Since water constitutes the main part of the flow, the overall flow goes down. The estimates from simulation show approximately 10 to $15 \%$ less flow which is in accordance with the observed results.

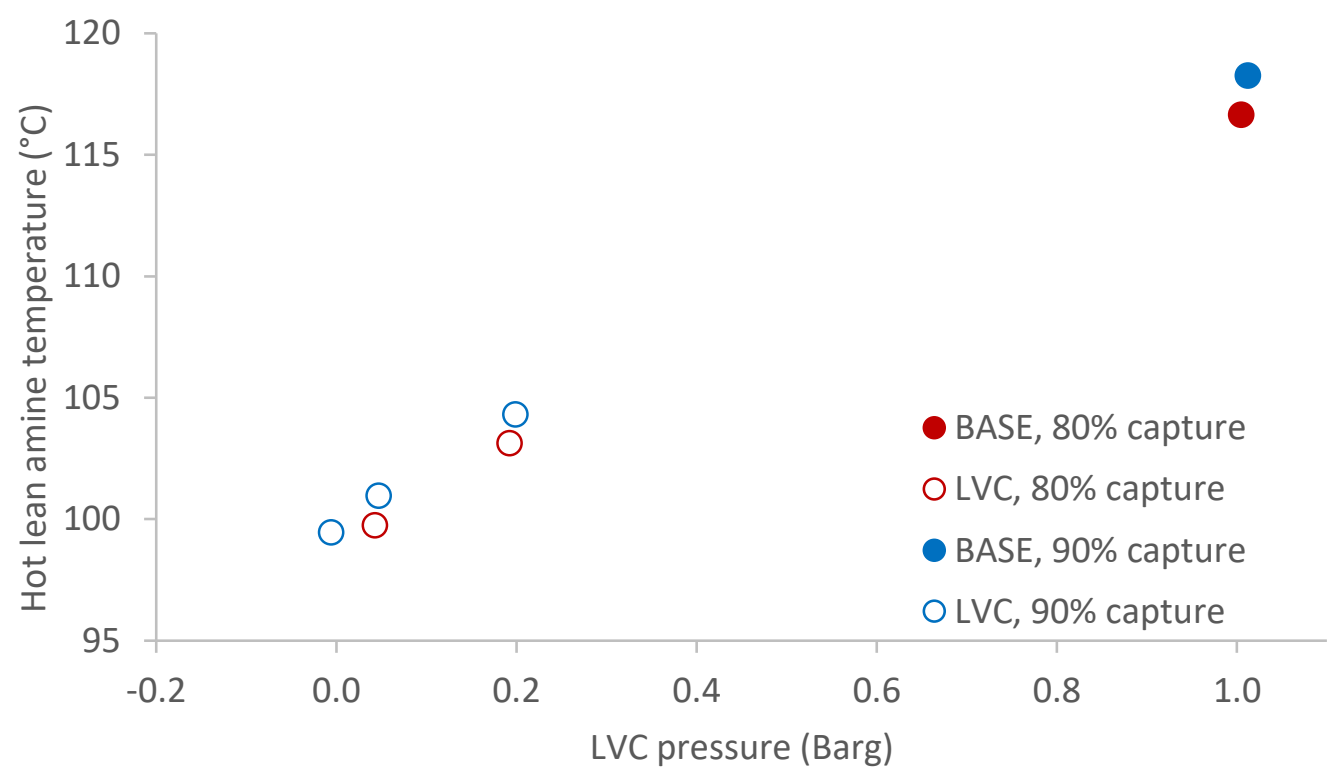

Figure 17. Hot lean amine temperature after flashing as a function of LVC pressure. Solvent flow rate: $200000 \mathrm{~kg} / \mathrm{h}$. 


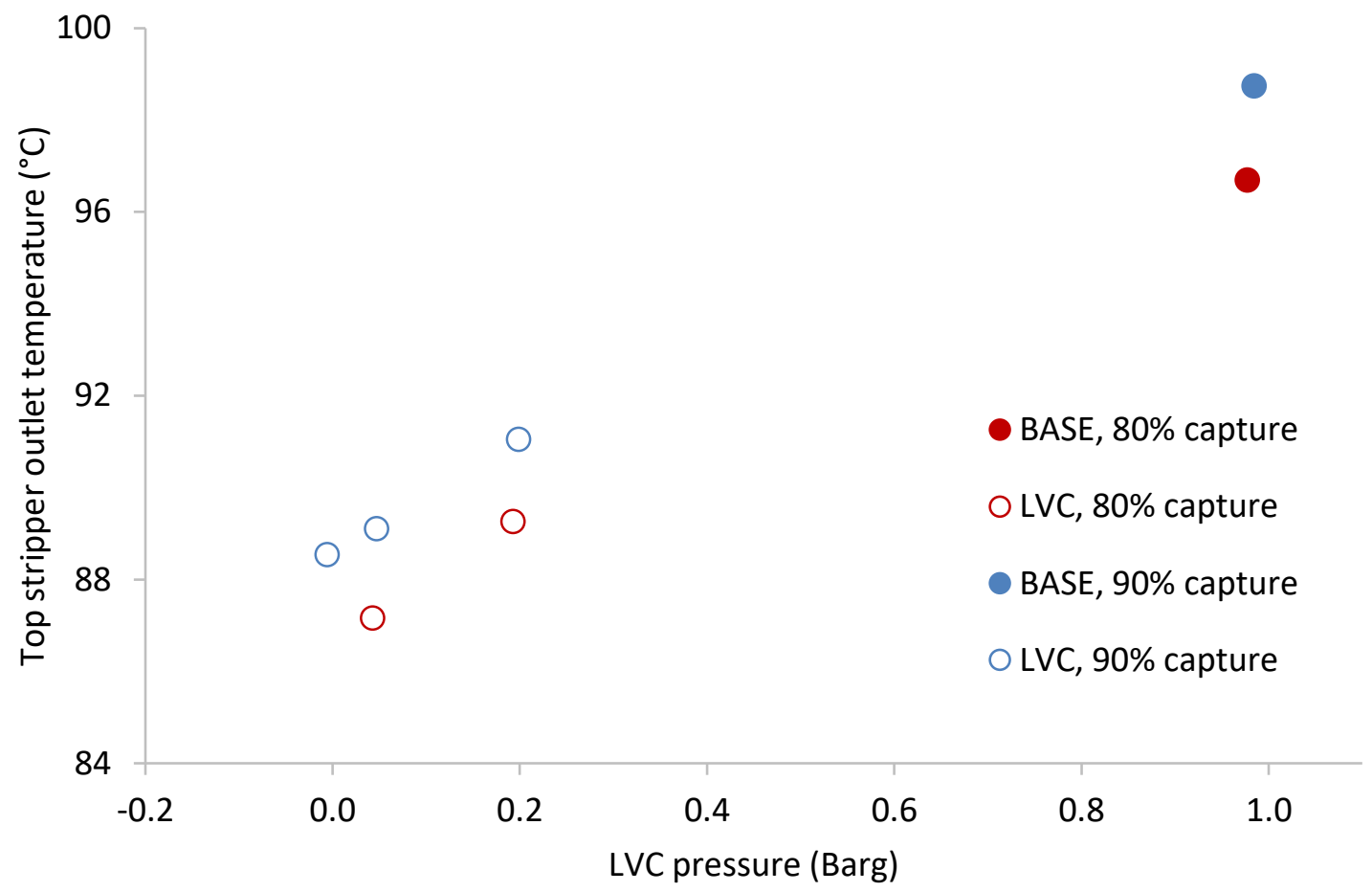

Figure 18. Top stripper outlet temperature as a function of LVC pressure. Solvent flow rate: $200000 \mathrm{~kg} / \mathrm{h}$.

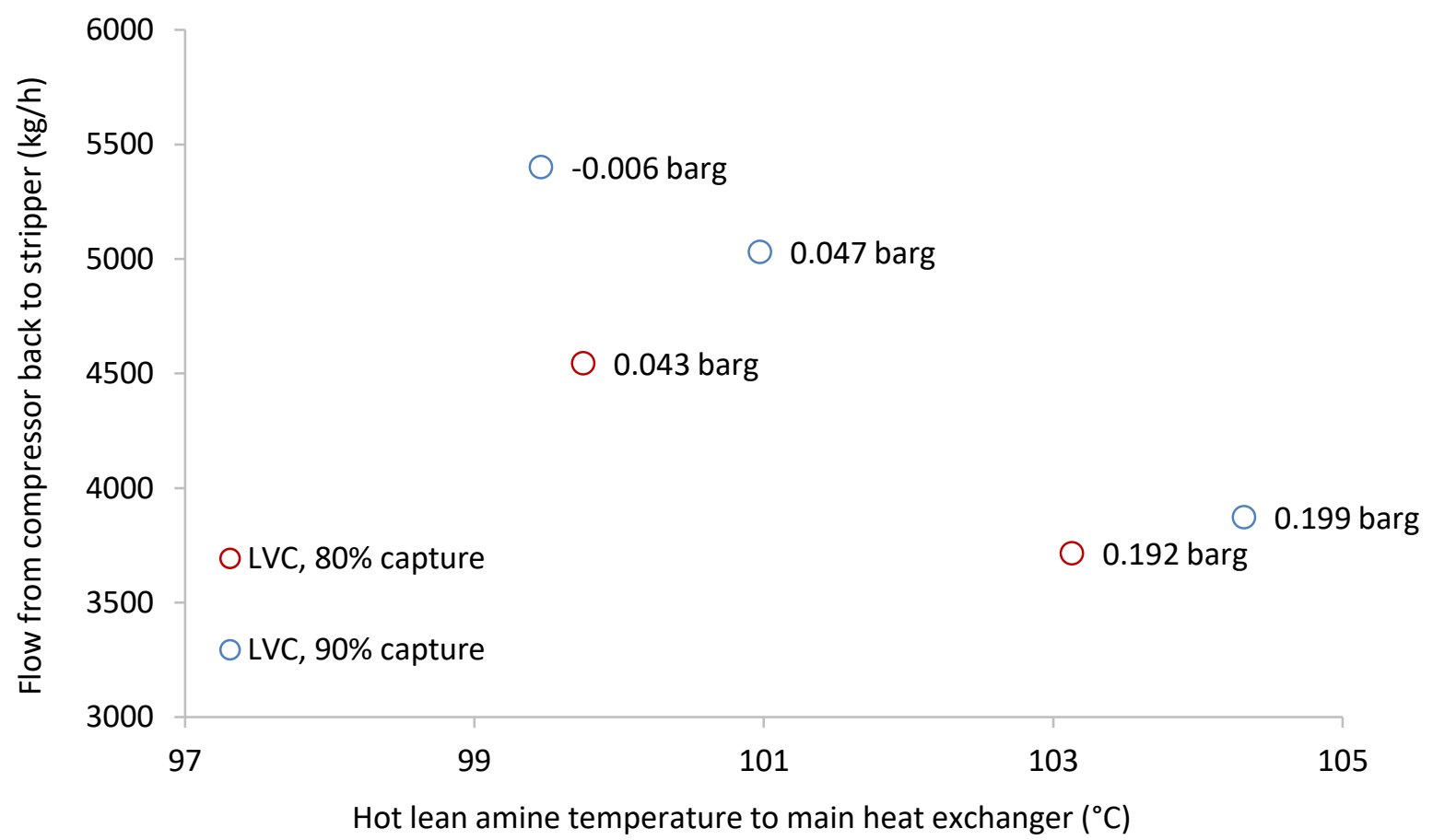

Figure 19. Flow from compressor to stripper as a function of hot lean amine temperature. Data labels indicate the LVC pressure. Solvent flow rate: $200000 \mathrm{~kg} / \mathrm{h}$. 


\subsection{Degradation products}

The amounts of solvent degradation products depicted in Figure 20 were observed during the campaign. In this figure it is seen that the solvent degradation is at a constant level while running the base cases. Solvent degradation seem to increase when the LVC is operated. There can be many explanations behind this observation. Simple explanations can be the release of iron from the LVC compressor, which was not used extensively before. The release of iron may have caused a catalytic decay of the amine. A second reason could be the high outlet LVC temperature $\left(190^{\circ} \mathrm{C}\right)$. The MEA content in this stream is small and may not have contributed significantly to the degradation. A third reason might be the high temperature vapour stream is fed directly into the stripper and contacts the solvent in the stripper. Resulting in potential degradation of solvent in contact with hot vapour from LVC. In the future the high gas temperatures could be resolved easily by a simple condensate spray (similar to a direct contact cooler (DCC)) into the compressed gas stream resulting in cooling.

A more detailed analysis would be valuable to understand if there is any link between operation of LVC and increased solvent degradation.

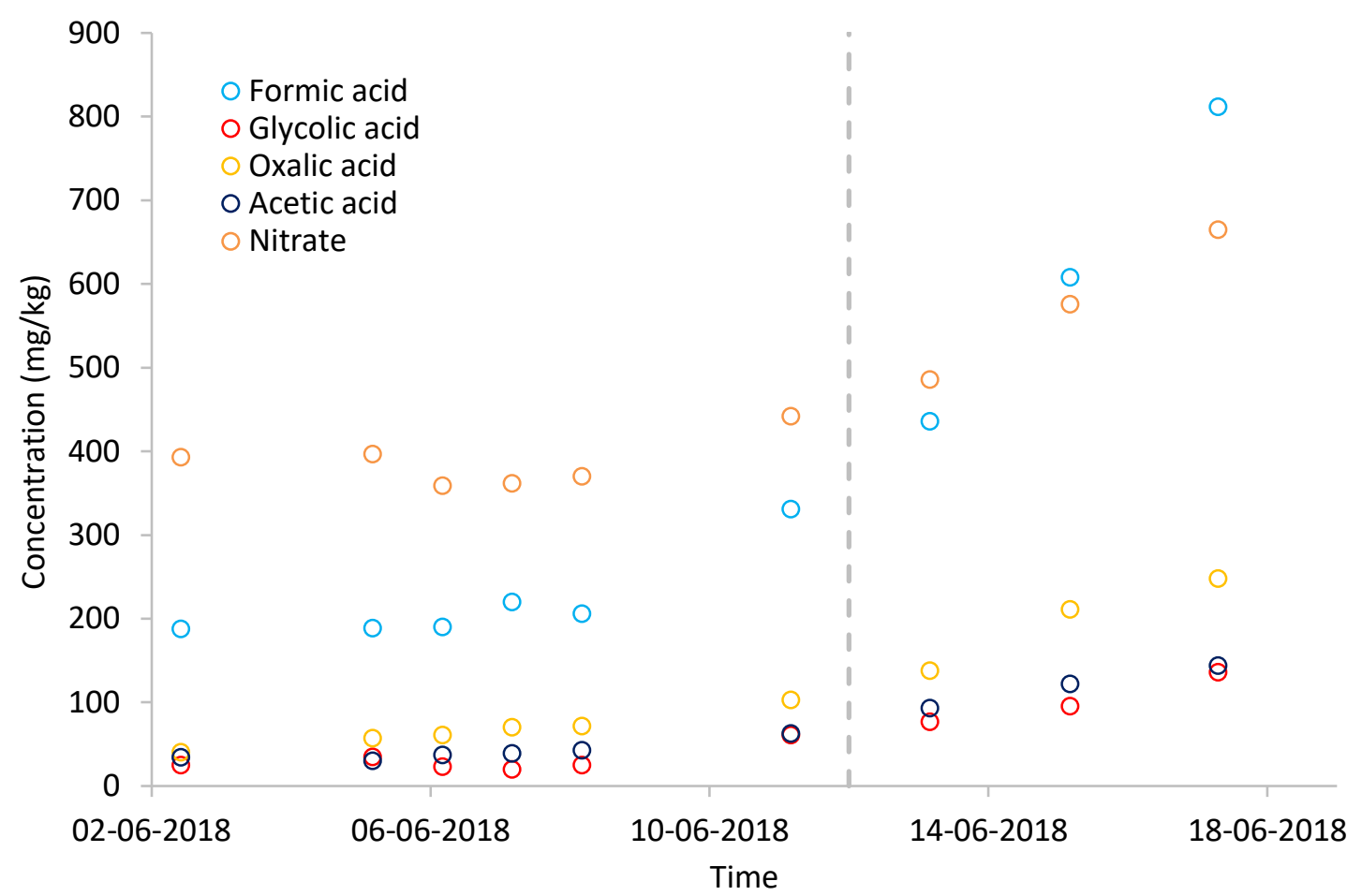

Figure 20. Concentration of degradation products as a function of time. Grey dashed line indicates the date that the LVC cases started. 


\section{Conclusion}

Testing of the lean vapour compressor unit at Technology Centre Mongstad using $30 \mathrm{wt} \%$ aqueous MEA and flue gas from the CCGT based CHP plant enriched with $\mathrm{CO}_{2}$ to $11-14 \%$ was carried out in June 2018. The aim of the campaign was to study the impact of the LVC performance on the $\mathrm{CO}_{2}$ capture efficiency and energy profile of the TCM amine plant. The flow rate of the exhaust gas was $35000 \mathrm{Sm}^{3} / \mathrm{h}$ and the $\mathrm{CO}_{2}$ inlet concentration to the absorber was 11 and 14 vol\% $\mathrm{CO}_{2}$. The overall operation of the plant was very steady, and the standard deviation and reproducibility of the process variables were satisfactory.

The LVC results are as expected compared to the trends in most cases: the lower the LVC operating pressure, the less the SRD. A maximum thermal energy reduction of $25 \%$ is possible (not including LVC electric energy). The LVC was performing with a certain amount of anti-surging and therefore the results are biased by the fact that an amount of the LVC power was spent in re-compression of the re-cycled flow. A significant amount of optimization, especially focused on reduction of LVC anti-surge, would be needed in the future. The LVC was running with approximately 25-40\% opening of the anti-surge valve, which it was not intended to do. The LVC is therefore in all cases using more energy than optimal. The typical electrical power consumption for the $\mathrm{LVC}$ was 0.1 to $0.2 \mathrm{GJ}$ electric/ton $\mathrm{CO}_{2}$. The impact of LVC on overall energy consumption is to some extend inconclusive due to anti-surge. The current results signify that LVC power consumption is just making it up for the SRD reduction, when considering efficiency factors. Alternative sustainable energy sources could be used for running the LVC, thereby preventing the need for extraction of high quality turbine steam. However the green energy source would most likely be used for electricity for the grid.

There is a strong indication that increased stripper pressure with LVC may decrease energy consumption and be beneficial to the thermal power used in the plant.

Results indicated that SRD had a non-linear u-type dependency on solvent flow rate. In the applied cases the lowest SRD is reached by the lowest solvent flow rate tested during the LVC campaign. A typical 23\% reduction of SRD was obtained for all solvent flow rates.

Higher $\mathrm{CO}_{2}$ inlet concentrations will reduce SRD while using LVC.

The application of $\mathrm{CO}_{2}$ capture technologies is important for the future of our climate. In this, optimization of processes are important. The presented results will help to enhance the accuracy $\mathrm{CO}_{2}$ capture engineering designs of the future.

\section{Acknowledgements}

The authors gratefully acknowledge the staff of TCM DA, Gassnova, Equinor, Shell and Total for their contribution and work at the TCM DA facility. The authors also gratefully acknowledge Gassnova, Equinor, Shell and Total as the owners of TCM DA for the financial support and contribution. 


\section{References}

[1] E. Sanchez Fernandez, E. J. Bergsma, F. de Miguel Mercader, E. L. V Goetheer, and T. J. H. Vlugt, "Optimisation of lean vapour compression (LVC) as an option for post-combustion CO2 capture: Net present value maximisation," Int. J. Greenh. Gas Control, vol. 11, pp. 114-121, 2012.

[2] M. Karimi, M. Hillestad, and H. F. Svendsen, "Positive and negative effects on energy consumption by inter-heating of stripper in CO2 capture plant," vol. 23, pp. 15-22, 2012.

[3] L. Dubois and D. Thomas, "Comparison of various configurations of the absorption-regeneration process using different solvents for the post-combustion $\mathrm{CO} 2$ capture applied to cement plant flue gases," Int. J. Greenh. Gas Control, vol. 69, pp. 20-35, 2018.

[4] H. M. Kvamsdal et al., "Modelling and simulation of the Esbjerg pilot plant using the Cesar 1 solvent," Energy Procedia, vol. 4, pp. 1644-1651, 2011.

[5] Y. Le Moullec and M. Kanniche, "Description and evaluation of flowsheet modifications and their interaction for an efficient monoethanolamine based post-combustion $\mathrm{CO} 2$ capture," Chem. Eng. Trans., vol. 21, no. March 2016, pp. 175-180, 2010.

[6] Y. Le Moullec and M. Kanniche, "Optimization of MEA based post combustion CO2 capture process: Flowsheeting and energetic integration," Energy Procedia, vol. 4, pp. 1303-1309, 2011.

[7] TCM, "The Open-source Centre at TCM." [Online]. Available: https://catchingourfuture.com/.

[8] D. Thimsen et al., "Results from MEA testing at the CO2 Technology Centre Mongstad. Part I: PostCombustion CO2 capture testing methodology," Energy Procedia, vol. 63, pp. 5938-5958, 2014.

[9] E. Gjernes et al., "Results from $30 \mathrm{wt} \%$ MEA Performance Testing at the CO2 Technology Centre Mongstad," Energy Procedia, vol. 114, pp. 1146-1157, 2017.

[10] O. M. Bade, J. N. Knudsen, O. Gorset, and I. Askestad, "Controlling amine mist formation in CO2 capture from Residual Catalytic Cracker (RCC) flue gas,” Energy Procedia, vol. 63, pp. 884-892, 2014.

[11] P. L. Fosbøl et al., "Benchmarking and Comparing First and Second Generation Post Combustion CO2 Capture Technologies," Energy Procedia, vol. 63, pp. 27-44, Jan. 2014.

[12] J. N. Knudsen, J. N. Jensen, P. Vilhelmsen, and O. Biede, "Experience with CO2 capture from coal flue gas in pilot-scale : Testing of different amine solvents," Energy Procedia, vol. 1, pp. 783-790, 2009. 
Appendix 1: Column temperature profiles

The TCM amine plant has a vast implementation of temperature probes in both the absorber and stripper. Figure 21 illustrates the absorber temperature profile of case 1A-1. It shows a characteristic bulge scenario with a maximum temperature near the top of the absorber due to the exothermic reaction of $\mathrm{CO}_{2}$ with amine. The decrease in temperature is due to water vaporization and cooling from the cold lean stream. The maximum temperature is $77^{\circ} \mathrm{C}$. This type of bulge is often observed at pinch conditions where the actual and equilibrium partial pressures are equal, indicating no driving force for mass transfer. The profiles of the remaining cases are not shown as they are very similar to the example given. There are four parallel temperature sensors, where the legend A refers to the temperature sensor close to the wall of the absorber. The legends B, C, and D are the temperature probes inside the packing at horizontal 1 meter distance from each other. The difference in the B, C, and D probes indicate to some extent the precision of the measurement or an uneven distribution of solvent and/or gas in the packing. A difference in the A probe compared to the rest might designate heat loss close to the absorber wall.

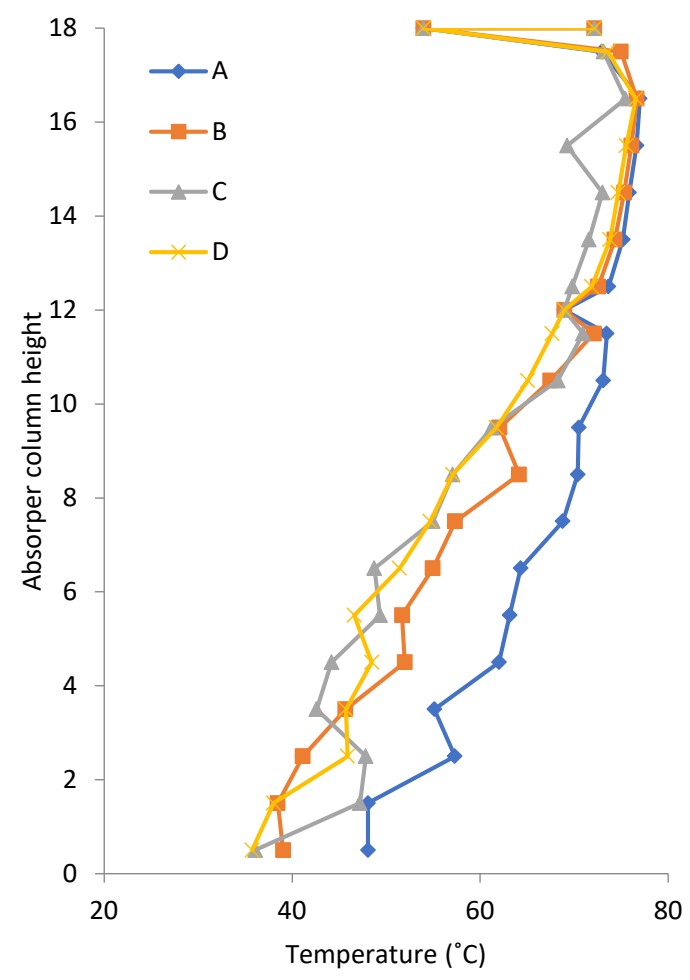

Figure 21. Case 1A-1 absorber temperature profile.

The stripper temperature profiles are more complex in nature. The TCM stripper does also have four parallel temperature sensors, placed similar to the absorber. A selection of three typical profiles (case 1A-1, 1C and 2A) are shown in Figure 22. These temperature profiles characterize the stripper performance, which in these cases are below, on, and above optimal conditions, respectively, with respect to steam consumption and $\mathrm{CO}_{2}$ desorption. The detailed explanation behind the phenomena and this type of observation given by Fosbøl et al. [11]. The basic phenomenon is mainly caused by condensation of water. Case 1A-1 (to the left) would be a condition which is receiving too little energy. The boil-up is quite small compared to the overall solvent flow in the column. The $\mathrm{CO}_{2}$ is desorbed in the stripper bed top and bottom, while the mid part of the column is inefficient. Case 2A (to the right) is opposite of the 
above case. It looks quite similar to the middle figure, however probe A (blue) has a steep drop in the top temperature. Also notice that case $2 \mathrm{~A}$ is missing data in the column top (probe $\mathrm{B}$ and $\mathrm{D}$ ), and the profile might therefore be misleading. Case $2 \mathrm{~A}$ exemplifies a condition which receives too much energy. The majority of the $\mathrm{CO}_{2}$ is desorbed in the column top - mainly performed by water condensation. Case 1C (in the middle) is close to optimal operating conditions. The profile is close to linear up through the column. There is a good balance between water condensation and $\mathrm{CO}_{2}$ desorption.

12 out of the 16 cases resemble case $1 \mathrm{~A}-1$ which receives too little energy. There is a good likelihood that the stripper is operating at non-pinch conditions. Case $1 \mathrm{C}$ is close to optimal pinch-point condition which means that the driving force for $\mathrm{CO}_{2}$ desorption is constant throughout the column height and the efficiency of the packing material is evenly distributed. Non-pinch conditions could indicate that the top or the bottom of the column is very efficient, while a large portion of the remaining column is inefficient.
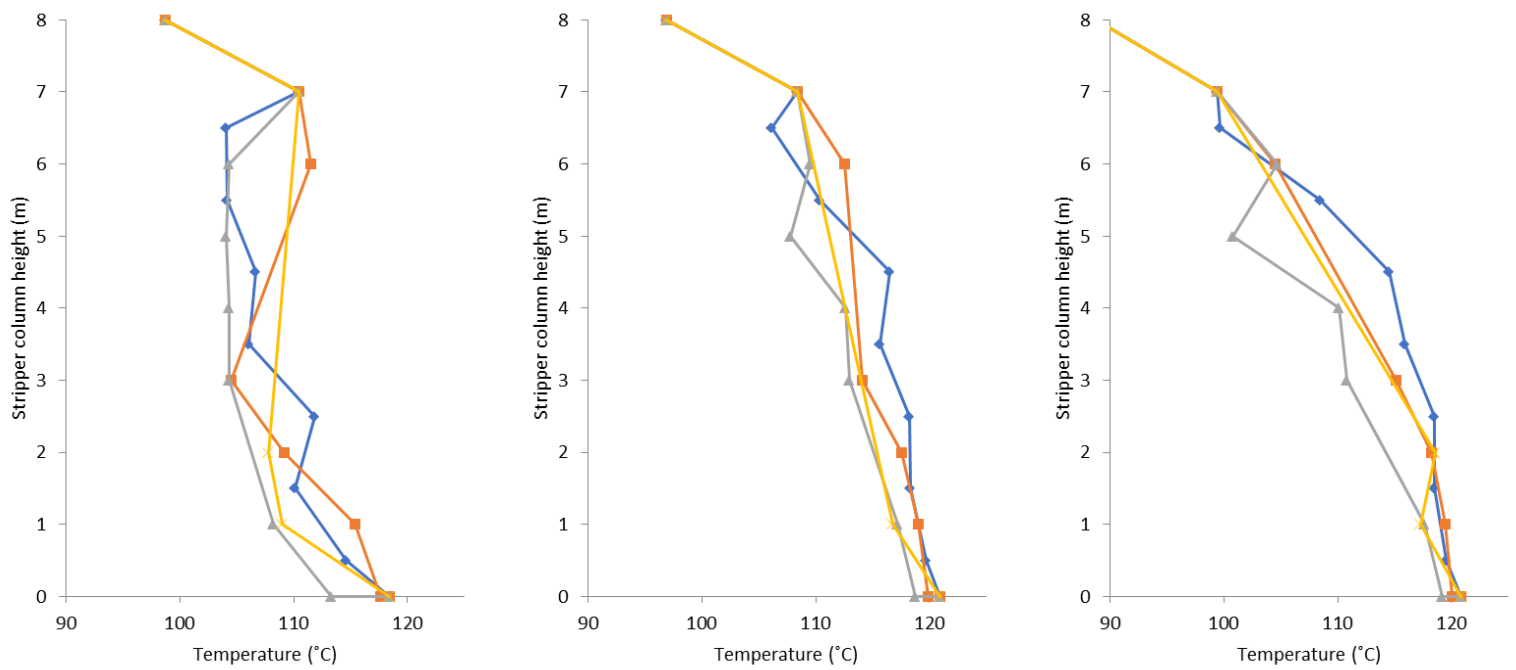

Figure 22. Stripper temperature profiles, from left: Case 1A-1, 1C, and 2A. Probe A (blue), B (red), C (grey), D (yellow). 